Review article

\title{
Reappraising striatal D1- and D2-neurons in reward and aversion
}

\author{
Carina Soares-Cunha ${ }^{\mathrm{a}, \mathrm{b}}$, Barbara Coimbra ${ }^{\mathrm{a}, \mathrm{b}}$, Nuno Sousa ${ }^{\mathrm{a}, \mathrm{b}}$, Ana J. Rodrigues ${ }^{\mathrm{a}, \mathrm{b}, *}$ \\ a Life and Health Sciences Research Institute (ICVS), School of Health Sciences, University of Minho, Braga, Portugal \\ b ICVS/3B's-PT Government Associate Laboratory, Braga, Guimarães, Portugal
}

\section{A R T I C L E I N F O}

\section{Article history:}

Received 24 March 2016

Received in revised form 16 May 2016

Accepted 22 May 2016

Available online 24 May 2016

\section{Keywords:}

Dopamine

Reward

Reinforcement

Aversion

Nucleus accumbens

Dorsal striatum

D1 dopamine receptor

D2 dopamine receptor

Mesolimbic

Nigrostriatal

Medium spiny neurons

\begin{abstract}
A B S T R A C T
The striatum has been involved in complex behaviors such as motor control, learning, decision-making, reward and aversion. The striatum is mainly composed of medium spiny neurons (MSNs), typically divided into those expressing dopamine receptor D1, forming the so-called direct pathway, and those expressing D2 receptor (indirect pathway). For decades it has been proposed that these two populations exhibit opposing control over motor output, and recently, the same dichotomy has been proposed for valenced behaviors. Whereas D1-MSNs mediate reinforcement and reward, D2-MSNs have been associated with punishment and aversion.

In this review we will discuss pharmacological, genetic and optogenetic studies that indicate that there is still controversy to what concerns the role of striatal D1- and D2-MSNs in this type of behaviors, highlighting the need to reconsider the early view that they mediate solely opposing aspects of valenced behaviour.
\end{abstract}

(C) 2016 Elsevier Ltd. All rights reserved.

\section{Contents}

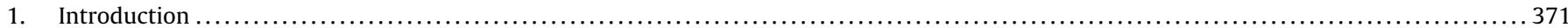

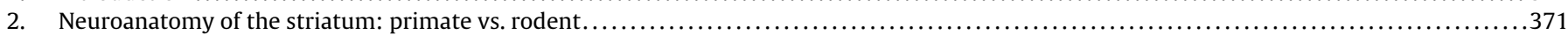

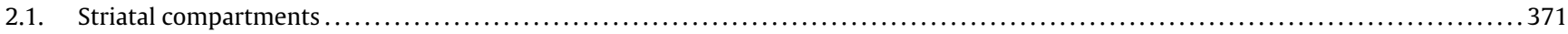

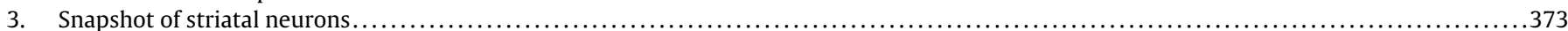

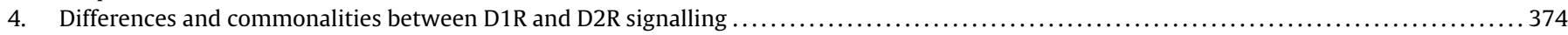

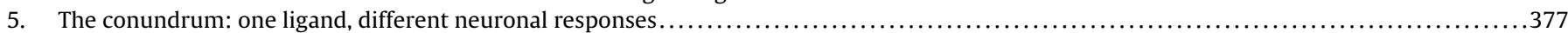

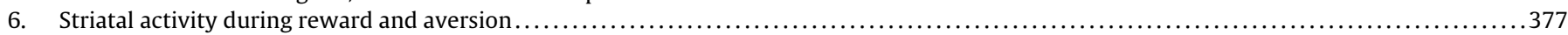

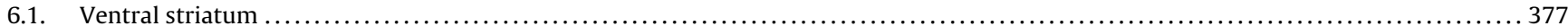

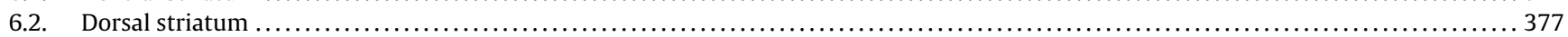

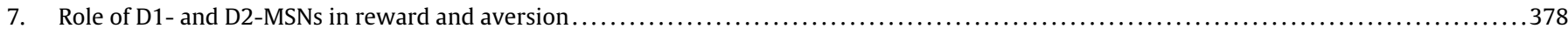

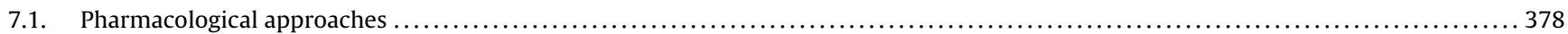

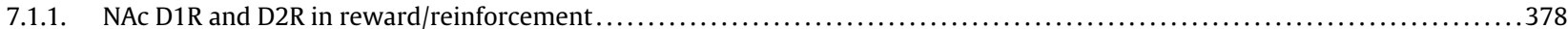

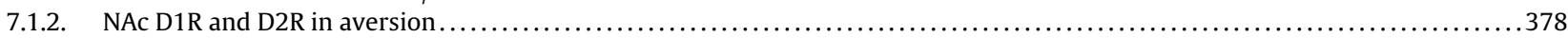

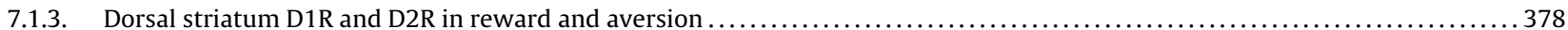

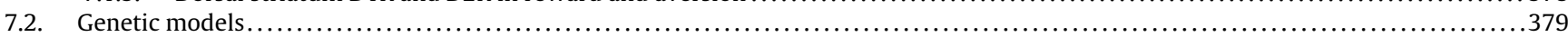

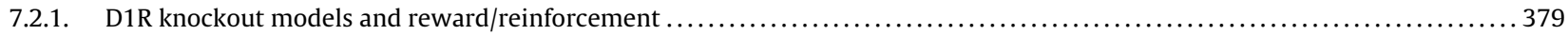

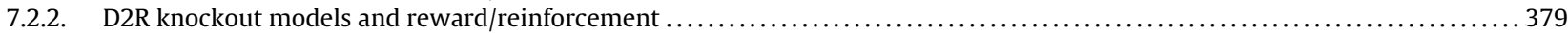

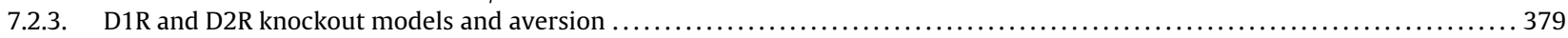

\footnotetext{
* Corresponding author at: Life and Health Sciences Research Institute (ICVS), School of Health Sciences, University of Minho, 4710-057, Braga, Portugal.

E-mail address: ajrodrigues@ecsaude.uminho.pt (A.J. Rodrigues).
} 


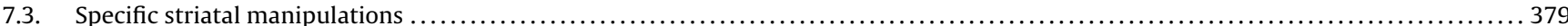

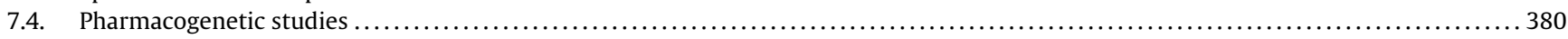

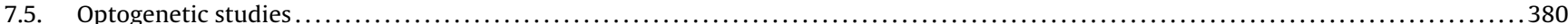

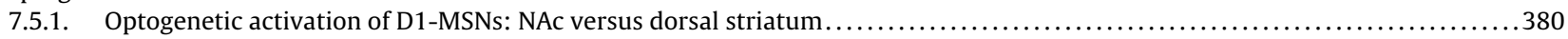

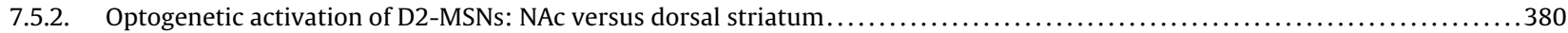

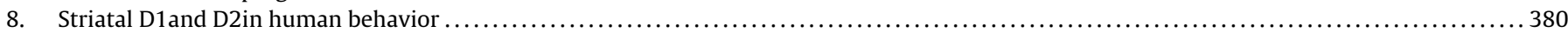

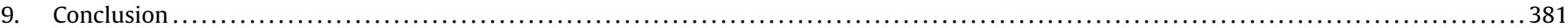

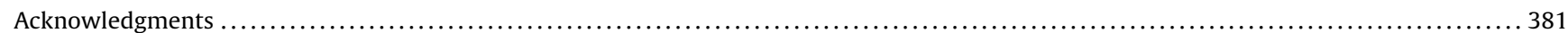

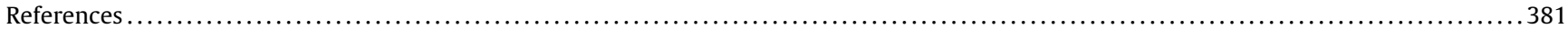

\section{Introduction}

For decades, researchers have been trying to dissect the role of striatal neurons in reward and reinforcement, and more lately in aversion and punishment. The study of the circuits underlying these behavioural dimensions is particularly relevant to better understand the basis of addiction and mood disorders, namely depression. For example, imaging studies showed that discrete circuits that are dependent on key elements such as the ventral tegmental area (VTA) and the ventral striatum suffer deep neuronal and structural changes in addicted individuals (reviewed by Koob and Volkow, 2010). Likewise, patients with mood disorders display reduced nucleus accumbens (NAc) volume and activation (Baumann et al., 1999; Heller et al., 2009). Moreover, animal studies have shown that different striatal populations contribute differently for depressive-like behaviour (Francis et al., 2015).

The development of new transgenic animal models and sophisticated tools such as optogenetics has provided key insights on the role of striatal neurons in behaviour but also raised some questions about the interpretation of earlier pharmacological and lesion studies. For more than 30 years it is hypothesized that medium spiny neurons (MSNs) expressing dopamine receptor 1 (D1R, D1-MSNs) or expressing dopamine receptor 2 (D2R, D2-MSNs) exert opposing control over motor output. Recently, this hypothesis has been extended, proposing that D1-MSNs mediate reinforcement and reward, whilst D2-MSNs mediate punishment and aversion. D1and D2-MSNs have been classically associated with the basal ganglia direct and indirect pathways, respectively, based on the studies showing segregation of these neuronal populations into distinct circuits. Yet, more recent anatomical and behavioral data argues against this simplistic framework. First, whereas the division of direct and indirect neurons based on the respective expression of $\mathrm{D} 1 \mathrm{R}$ and D2R in dorsal striatum is accurate, this does not hold true for the ventral striatum since the indirect pathway contains a mixture of both D1- and D2-MSNs (Kupchik et al., 2015; Lu et al., 1998). In addition, behavioral studies suggest that the same type of neuron but in different striatal locations can selectively drive opposing behaviors, namely reward and aversion (Al-Hasani et al., 2015). Other studies suggest that in fact, both ventral striatal subpopulations can mediate incentive motivation and reinforcement (Soares-Cunha et al., 2016). Similarly, in the dorsal striatum, both subpopulations are also involved in positive reinforcement, but support different action strategies (Vicente et al., 2016).

In this review we will discuss the commonalities and divergences between pharmacological, genetic and optogenetic studies regarding the role of dorsal and ventral striatal neurons in mediating the responses to reward and aversion and provide a critical analysis on the contribution of D1R- or D2R-expressing neurons in this process.

\section{Neuroanatomy of the striatum: primate vs. rodent}

Despite several bridges that are commonly made between rodent and human anatomy, it is important to highlight the major anatomical sub-regions that constitute the striatum of these two phylogeneticaly distinct species (Fig. 1). The human dorsal striatum is subdivided into caudate nucleus and putamen by the internal capsula (Graybiel and Ragsdale, 1978) in its most dorsal portion. The caudate nucleus receives inputs mostly from cortical regions (prefrontal and orbitofrontal cortices) and putamen receives mainly excitatory inputs from sensorimotor areas (Graybiel and Rauch, 2000; Krack et al., 2010). The human ventral striatum is composed by the NAc (and olfactory tubercle), which receives projections from both prefrontal and limbic structures, and acts as a motor-limbic interface, being involved in motor, emotional and motivational processes (Fig. 1A). Thalamostriatal projections are also different from dorsal and ventral striatum. The central medial nucleus and the dorsolateral parafascicular (PF) of the intralaminar complex innervate the putamen, whereas caudal PF innervates the caudate (McFarland and Haber, 2000; Smith et al., 2009, 2004). Ventral striatum receives projections from rostral PF but also from midline nuclear group nuclei (Giménez-Amaya et al., 1995; Smith et al., 2009, 2004).

Rodent striatum is composed by dorsal striatum and ventral striatum (Voorn et al., 2004). Dorsal striatum is sub-divided into dorsomedial striatum (DMS), which mainly receives inputs from the most ventral region of the prefrontal cortex (infralimbic cortex) and the dorsolateral striatum (homologue to the primate putamen) that mainly receives projections from the motor cortex (Voorn et al., 2004). Similarly as in primates, DLS is mainly innervated by the dorsolateral PF and DMS receives projections from medial PF, whereas the NAc receives projections from midline nuclear group including the parataenial and the intermediodorsal nucleus (Berendse et al., 1992; Haber, 2011; Lanciego et al., 2004).

The rodent ventral striatum is composed by the NAc (Zahm and Brog, 1992; Zahm and Heimer, 1990), subdivided in the core (NAcc) and shell (NAcs) portions, which receives projections from the prelimbic and infralimbic cortex (Lanciego et al., 2004; Russo and Nestler, 2013; Voorn et al., 2004; Yin and Knowlton, 2006) (Fig. 1B). In addition, this striatal region also receives projections from the ventromedial PF (Lanciego et al., 2004; Smith et al., 2004; Voorn et al., 2004) (Fig. 1B).

Importantly, recent studies using transgenic animals, novel viral tools and anterograde/retrograde tracers have provided a comprehensive map of direct inputs to striatal neurons and interneurons, showing a far more complex network than initially anticipated, and which may be determinant for future functional investigation of striatal circuits (Guo et al., 2015; Wall et al., 2013). Moreover, striatal regions strongly project to different regions of the brain, including the basal ganglia and different cortical and thalamic regions (Guo et al., 2015; Haber, 2003; Nauta et al., 1978; Sesack and Grace, 2010; Smith et al., 2004; Watabe-Uchida et al., 2012) (inputs and outputs are summarized in Fig. 1C).

\subsection{Striatal compartments}

The mammalian striatum is composed of two components, the patches and the matrix, which contain different neurochemical 
A

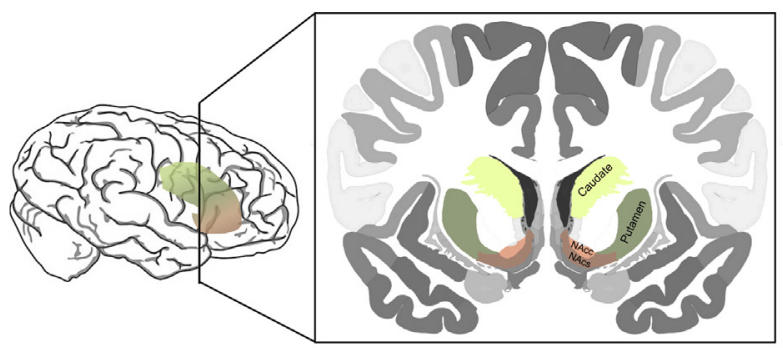

B

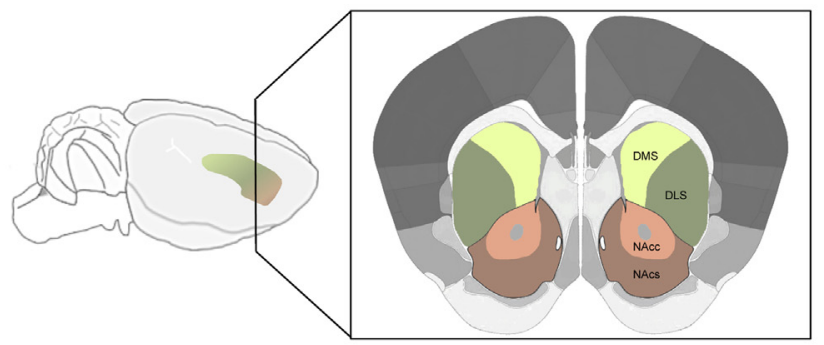

C

\begin{tabular}{l} 
Medial parafascicular nucleus \\
\hline Somatosensory cortex \\
Infralimbic cortex \\
Cingulate cortex \\
Visual cortex \\
\hline Ventral tegmental area \\
Basolateral amygdala \\
Dorsal raph nucleus \\
External globus pallidus \\
Laterodorsal tegmental nucleus \\
\hline
\end{tabular}

Dorsolateral parafascicular nucleus

Somatosensory cortex

Motor cortex

Cingulate cortex

Visual cortex

Substantia nigra pars compacta

Basolateral amygdala

Dorsal raph nucleus

External globus pallidus

Substantia nigra pars compacta

\begin{tabular}{l} 
Thalamic intermediodorsal nucleus \\
Thalamic central medial nucleus \\
\hline Prelimbic cortex \\
Dorsal agranular insular cortex \\
\hline Mid rostrocaudal basal amygdaloid \\
complex \\
Substantia nigra pars reticulata \\
Medial substantia nigra pars \\
compacta \\
Laterodorsal tegmental nucleus
\end{tabular}

\section{Thalamic paraventricular nucleus}

Infralimbic cortex

Ventral agranular insular cortex

Rostral and caudal basal amygdaloid

complex

Hippocampus

Ventral tegmental area

Substantia nigra pars compacta

Retrorubral nucleus

Laterodorsal tegmental nucleus

Bed nucleus of stria teminalis
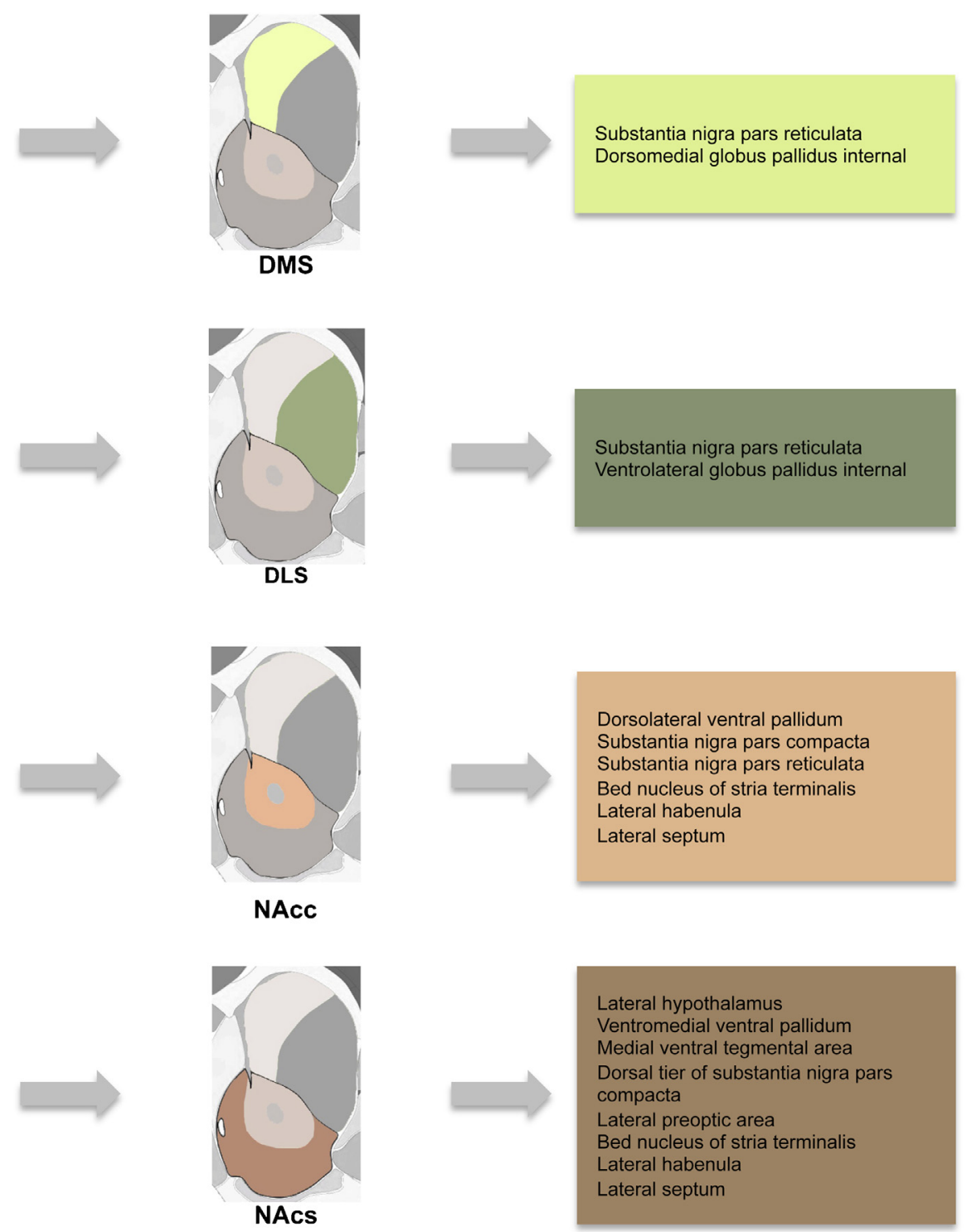

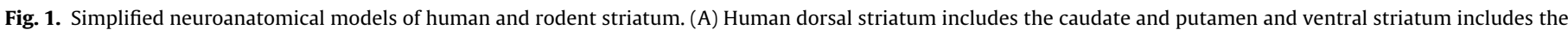

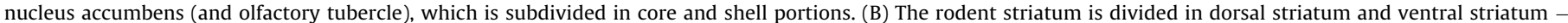

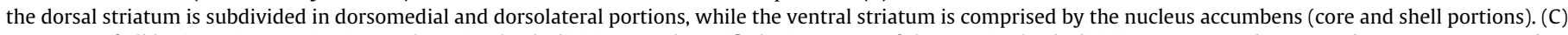

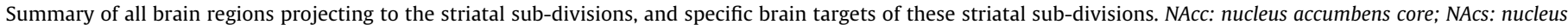
accumbens shell; DMS: dorsomedial striatum; DLS: dorsolateral striatum.

markers (Graybiel and Ragsdale, 1978; Herkenham and Pert, 1981; Olson et al., 1972). Patches (or striosomes) represent around 10\% of striatal volume and are densely enriched in $\mu$-opioid receptors, substance $\mathrm{P}$ and contain little expression of cholinergic markers (Bolam et al., 1986; Graybiel and Ragsdale, 1978; Herkenham and
Pert, 1981). In addition, MSNs contained in the patch compartment receive inputs from limbic and frontal regions (Donoghue and Herkenham, 1986; Gerfen, 1985; Kincaid and Wilson, 1996; Ragsdale and Graybiel, 1988), and from a distinct sub-set of neurons of the substantia nigra pars compacta (SNpc) (Gerfen, 1985; 
Gerfen and Young, 1988). The matrix is highly enriched in cholinergic markers, calbindin and somatostatin (Gerfen, 1985, 1984; Graybiel et al., 1986; Graybiel and Ragsdale, 1978), and the MSNs contained in this compartment receive inputs from cortex, thalamus (Fujiyama et al., 2006, 2006; Sadikot et al., 1992) and VTA (Gerfen et al., 1987).

Interestingly, while D1-MSNs (assuming to be those that express dynorphin) projecting to the mesencephalon and D2-MSNs projecting (assuming to be those that express enkephalin) to the substantia nigra pars reticulata $(\mathrm{SNr})$ are contained in the matrix and patches, D2-MSNs projecting to the SNpc are exclusive to patches (Gerfen et al., 1990; Gerfen and Young, 1988).

\section{Snapshot of striatal neurons}

Striatal neurons represent a homogeneous neuronal population, constituted mainly by GABAergic MSNs, which represent about 95\% of all neurons.

Dorsal striatal MSNs are traditionally subdivided into two distinct subtypes based on their axonal targets: striatonigral MSNs which directly project to output nuclei of the basal ganglia, namely to the globus pallidus internal (GPi), SNr and VTA (direct pathway; Fig. 2); and the striatopallidal MSNs, which reach output nuclei indirectly, by projecting to the GP external (GPe) and subthalamic nuclei (STN) (indirect pathway; Fig. 2B). Activation of the direct pathway briefly supresses pallidum activity allowing thalamocortical activation, facilitating movement, whereas activation of the indirect pathway further inhibits thalamocortical neurons and inhibits movement (Groenewegen, 2003; Parent and Hazrati, 1995; Takakusaki et al., 2004). These two MSN populations express different molecules; striatonigral/direct MSNs express D1R, substance P and dynorphin, and striatopallidal MSNs express D2R, adenosine receptor 2a $\left(\mathrm{A}_{2} \mathrm{aR}\right)$, and enkephalin (Gerfen, 1992; Heiman et al., 2008; Kawaguchi, 1997; Lobo et al., 2006).

Dorsal striatal MSNs show some degree of topographical segregation. While the most dorsal portion of the dorsal striatum presents a random distribution of D1- and D2-MSNs, the most caudal portion of the dorsal striatum is comprised almost exclusively by D1-MSNs (Gangarossa et al., 2013b).

In the NAc (NAC is assumed as the ventral striatum for the purpose of this review), there is a similar direct/indirect dichotomy, although evidence gathered in the last years shows that the discrete separation of D1-MSNs and D2-MSNs in direct/indirect pathway is not precise (Fig. 2). The direct pathway involves NAc projections to the ventral mesencephalon (SN and VTA) and from there to the mediodorsal thalamus (MDT). The indirect pathway (Fig. 2D) travels through the ventral pallidum (VP) and subthalamic nucleus before reaching the ventral mesencephalon. Whereas NAc core projects to dorsolateral VP (dIVP) and SNr, and NAc shell to ventromedial VP (vmVP) and VTA (Zahm and Heimer, 1990). Akin to dorsal striatum, in the direct pathway, NAc-SNr/VTA connections are entirely mediated by D1-MSNs; however, indirect pathway NAcVP projections have major contributions of both types of MSNs (Kupchik et al., 2015; Lu et al., 1998). Because the VP serves as an output nucleus, sending projections outside of the basal ganglia to the MDT, this suggests that both D1- and D2-MSN populations can inhibit/disinhibit thalamic activity, contrary to dorsal striatum (Kupchik et al., 2015).

Similarly to what is observed in the dorsal striatum, accumbal D1-MSNs and D2-MSNs also show differential topographical distribution. D1-MSNs are equally distributed throughout the NAcc and NAcs (Gangarossa et al., 2013a). D2-MSNs are homogeneously distributed in the NAcc, but in the NAcs they are more expressed in the medial and ventral NAcs (Gangarossa et al., 2013a).
Despite the distinctive molecular fingerprinting of the two MSN subpopulations, it has been suggested that $5-15 \%$ of dorsal striatum MSNs can express both D1R and D2R (Bertran-Gonzalez et al., 2008; Lester et al., 1993; Perreault et al., 2011). These neurons coexpressing D1R and D2R project to GPe and GPi, as well as $\mathrm{SNr}$ and VTA (Deng et al., 2006; Wang et al., 2006, 2007), though their exact role remains undisclosed. Importantly, it has been suggested that $>90 \%$ the D1R/D2R co-expressing neurons in the NAc present $\mathrm{D} 1 \mathrm{R}-\mathrm{D} 2 \mathrm{R}$ receptor heterodimers, whereas in dorsal striatum, heterodimers are only detected in $\sim 25 \%$ of $D 1 R / D 2 R$ co-expressing neurons (Perreault et al., 2010). The function of these heterodimers is still unknown but they have been suggested to exhibit pharmacological and cell-signaling properties distinct from its constituent receptors (Perreault et al., 2014); and these have been associated with depression and addiction (Perreault et al., 2014, 2010). However, the existence of such heterodimers in vivo has also been questioned by recent studies (Frederick et al., 2015).

The remaining $5 \%$ of striatal neurons are interneurons (Graveland and DiFiglia, 1985) (vide Table 1). Interneurons play a very important role in basal ganglia function, by controlling MSN excitability directly or indirectly, and affecting behaviour (Charara et al., 2003; Gittis and Kreitzer, 2012; Hikida et al., 2001; Kaneko et al., 2000; Tepper et al., 2010; Tritsch and Sabatini, 2012).

Interneurons include large tonically active cholinergic neurons (CIN) (Aosaki et al., 1994; Dautan et al., 2014; Morris et al., 2004) that have been implicated in the control of the activation/modulation of the direct and indirect striatal pathways (Cachope et al., 2012; Centonze et al., 2003; Hikida et al., 2001; Kaneko et al., 2000; Maurice et al., 2004; Pisani et al., 2000; Threlfell et al., 2012; Tozzi et al., 2011; Witten et al., 2010) and constitute the main cholinergic source of this brain region (at least proven to be functional so far) (Bjorklund et al., 1996). Yet, it is important to refer that a neuroanatomical study has shown that the brainstem cholinergic areas pedunculopontine nuclei and the laterodorsal tegmentum also provide a direct innervation of the striatal complex (Dautan et al., 2014). CINs also express dopamine receptors, including D2-R and D5-R reviewed in (Surmeier et al., 2007). Interestingly, specific stimulation of CIN interneurons evokes dopamine release in a $\beta 2$ nicotinic $A C h$ receptor ( $\mathrm{AAChR}$ )-dependent manner (Cachope et al., 2012; Maurice et al., 2004; Pisani et al., 2000; Tozzi et al., 2011).

The second class of interneurons are the fast spiking GABAergic (FS) interneurons, which characteristically express parvalbumin and are similar to the FS interneurons present in the cortex and hippocampus (Bevan et al., 1998; Tepper and Bolam, 2004). This particular neuronal population conveys its primary inhibitory synapses to both D1-MSNs and D2-MSNs (Bennett and Bolam, 1994; Gittis et al., 2010; Kreitzer and Malenka, 2008; Lapper et al., 1992; Planert et al., 2010; Sidibé and Smith, 1999; Tepper et al., 2010), providing a strong feed-forward inhibition that shapes the firing patterns of MSNs (Gittis et al., 2010; Planert et al., 2010; Tepper et al., 2008).

Another population of interneurons are the low threshold spiking (LTS) GABAergic interneurons that express somatostatin, neuropeptide $\mathrm{Y}$ and nitric oxide synthase, and are involved in long-term plasticity (English et al., 2012; Ibáñez-Sandoval et al., 2015, 2010; Kreitzer, 2009; Sidibé and Smith, 1999; Vuillet et al., 1989). Less studied are the tyrosine hydroxylase and calretinin striatal interneurons, which present sparse connections with MSNs (Table 1).

Despite their low number, interneurons can exert a very significant role in the control of striatal circuit activity and establishment of behavioural conditioning in vivo.

It is important to note that there are species differences in the density of these neuronal subtypes within the striatum. For example, primates contain more interneurons than rodents and have 
A

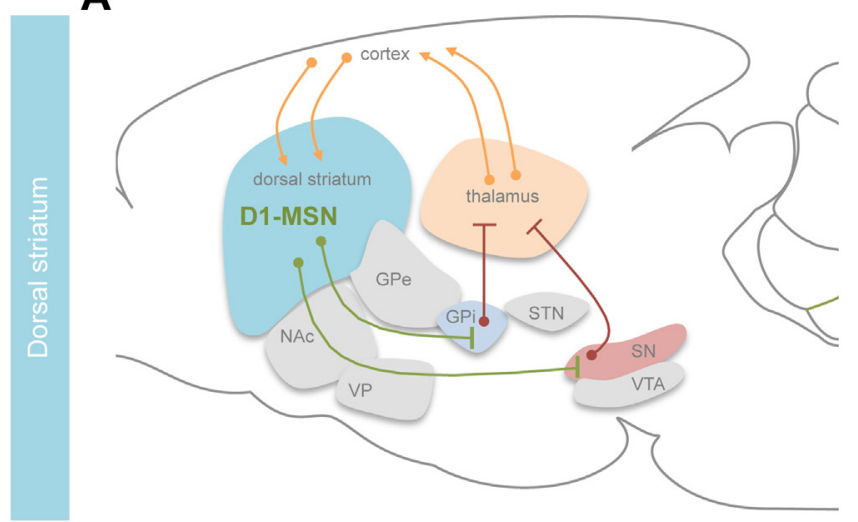

C

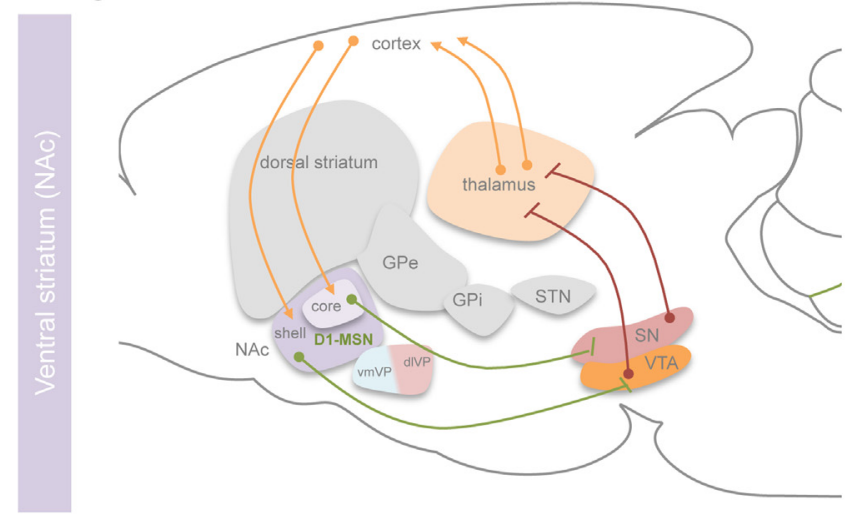

B

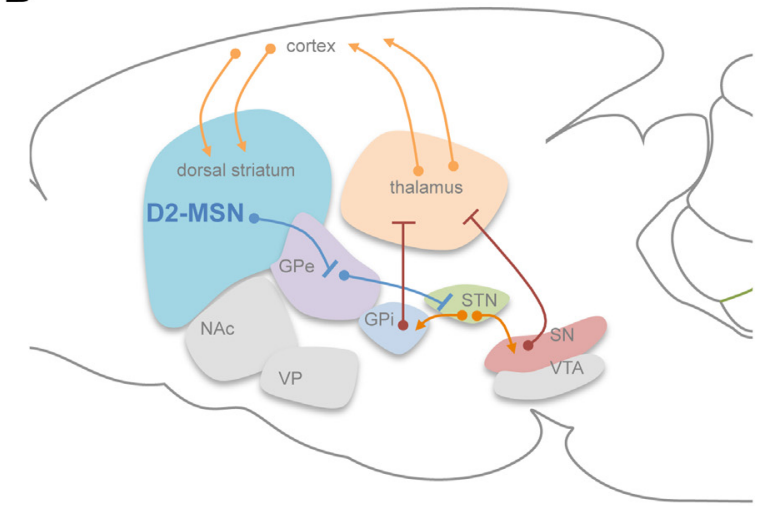

D

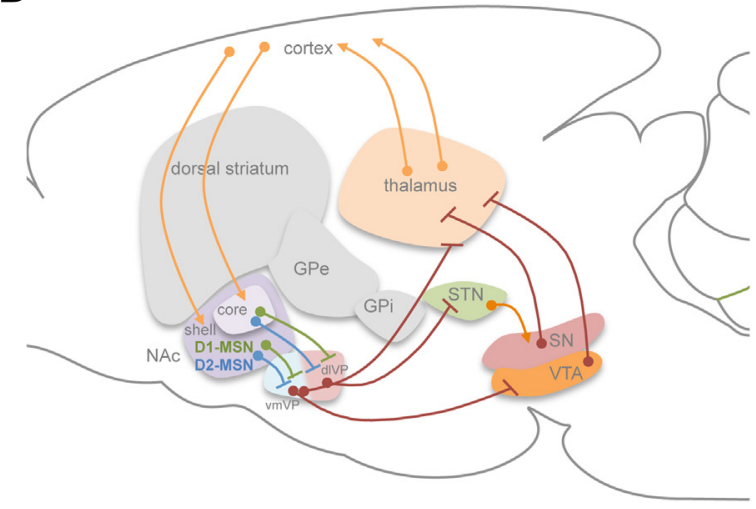

\footnotetext{
- D1 MSN GABAergic projections

- D2 MSN GABAergic projections

$\longrightarrow$ Glutamatergic projections

$\sim$ GABAergic projections
}

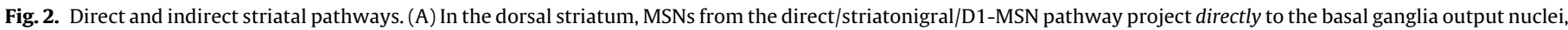

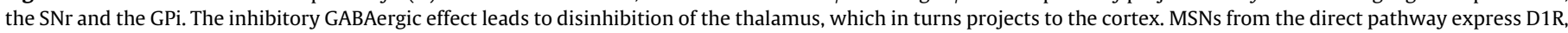

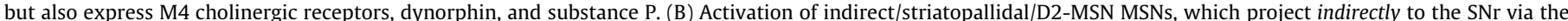

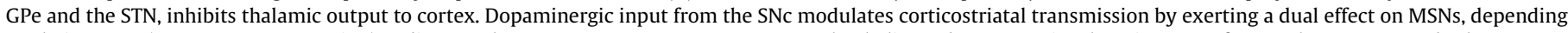

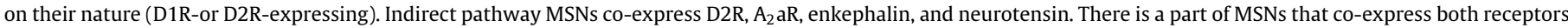

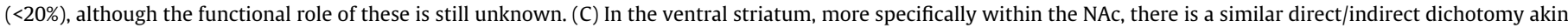

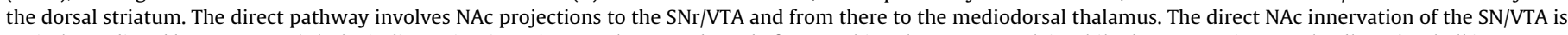

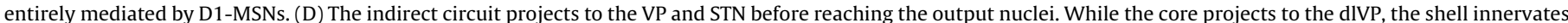

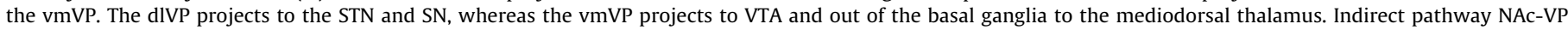

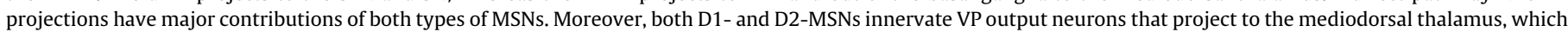

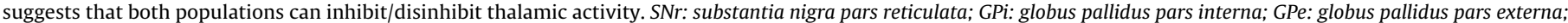

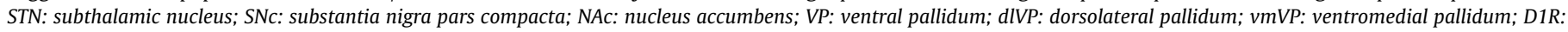
dopamine receptor 1; D2R: dopamine receptor 2; $A_{2}$ aR: adenosine receptor $2 a$.

more calretinin-positive and parvalbumin-positive interneurons in the dorsal striatum in comparison to rodents (Graveland et al., 1985; Wu and Parent, 2000).

Importantly, since interneurons also express dopamine receptors (reviewed in Tritsch and Sabatini, 2012), this complicates the use of specific agonists/antagonists or genetic approaches relying on the expression of these receptors to study the function of D1and D2-MSNs.

\section{Differences and commonalities between D1R and D2R signalling}

Dopamine activation of G-protein coupled dopamine receptors (D1R-D5R) excites or inhibits MSNs by modulating the gating and trafficking of voltage-dependent and ligand-gated (ionotropic) ion channels located in the cell membrane (Surmeier et al., 2007). The separation of the two major classes of dopamine receptors is based on intrinsic structural, pharmacological, and signalling properties: D1Rs and D5Rs are grouped in the D1R-like receptor subfamily, while the D2Rs, D3Rs and D4Rs are clustered in the D2R-like receptor subfamily (Beaulieu and Gainetdinov, 2011).

The genes encoding D1R are contained in a single exon; however, the same is not true for D2Rs. These receptors can be alternatively spliced, giving rise to several isoforms with distinct properties and subcellular localization (reviewed in D'souza, 2010). Pharmacological studies show that D2R-like receptors present a higher affinity towards dopamine when compared with the D1R subfamily, which can reach 10- to 100-fold (Beaulieu and Gainetdinov, 2011). D3Rs and D4Rs present the highest affinity to dopamine binding and D1R displays the lowest. Although both dopamine receptor subfamilies are GPCRs, being able to activate heterotrimeric $G$ proteins, the second messengers and effector proteins activated by both receptor classes vary greatly and often mediate opposite effects (Beaulieu and Gainetdinov, 2011). 
Table 1

Summary of the different types of striatal cells, their properties and dopamine receptor expression.

\begin{tabular}{|c|c|c|c|}
\hline Type of striatal cell & Properties & $\begin{array}{l}\text { Dopamine receptor } \\
\text { expression? }\end{array}$ & References \\
\hline \multicolumn{4}{|c|}{ Medium spiny neurons (MSNs) (90-95\%) } \\
\hline D1-MSNs & $\begin{array}{l}\text { Presence of D1R, dynorphin and substance P. } \\
\text { Low input resistance, inward rectification, and a long delay to initial } \\
\text { spiking. } \\
\text { Synapse with both D1-MSNs and with D2-MSNs. }\end{array}$ & D1R & $\begin{array}{l}\text { Cepeda et al., 2008; Gerfen, } \\
\text { 1985; Gertler et al., } 2008\end{array}$ \\
\hline D2-MSNs & $\begin{array}{l}\text { Presence of D2R, enkephalin and adenosine receptor } 2 a\left(A_{2} a\right) \text {. } \\
\text { Low input resistance, inward rectification, and a long delay to initial } \\
\text { spiking; increased excitability. } \\
\text { Synapse within each other and onto the striatopallidal pathway }\end{array}$ & $\mathrm{D} 2 \mathrm{R}$ & $\begin{array}{l}\text { Cepeda et al., 2008; Gerfen, } \\
\text { 1985; Gertler et al., } 2008\end{array}$ \\
\hline $\begin{array}{l}\text { D1/D2-MSN } \\
(5-15 \%)\end{array}$ & $\begin{array}{l}\text { Co-expression of D1R and D2R, expression of dynorphin and } \\
\text { enkephalin. } \\
\text { Some neurons present a D1R-D2R heterodimer. } \\
\text { Medium-sized spiny projection neurons, with enhanced dendritic } \\
\text { branching. }\end{array}$ & $\mathrm{D} 1 \mathrm{R}$ and $\mathrm{D} 2 \mathrm{R}$ & $\begin{array}{l}\text { Choi et al., 2009; Hasbi et al., } \\
\text { 2011; Lee et al., 2004; } \\
\text { Perreault et al., } 2012\end{array}$ \\
\hline \multicolumn{4}{|l|}{ GABAergic Interneurons (3-4\%) } \\
\hline Fast spiking interneurons (FS) & $\begin{array}{l}\text { Presence of parvalbumin. } \\
\text { Small diameter somata and aspiny dendrites that branch modestly. } \\
\text { Short-duration spikes, high frequency firing. } \\
\text { Form gap junctions with other FS interneurons; Strong and dense } \\
\text { projections to MSNs. }\end{array}$ & $>70 \% \mathrm{D} 5 \mathrm{R}$ & $\begin{array}{l}\text { Bevan et al., 1998; Kawaguchi, } \\
\text { 1997; Kreitzer, 2009; Kubota } \\
\text { and Kawaguchi, 2000; Tepper } \\
\text { et al., 2010; Tepper and Bolam, } \\
2004\end{array}$ \\
\hline NPY neurogliaform neurons & $\begin{array}{l}\text { Presence of neuropeptide Y. } \\
\text { Compact and highly branched dendritic and local axonal arborizations. } \\
\text { Low threshold calcium spikes (LTS) and a prolonged calcium } \\
\text { dependent plateau potential. } \\
\text { Second major class of projecting interneuron in the striatum. }\end{array}$ & $?$ & $\begin{array}{l}\text { English et al., 2012; } \\
\text { Ibáñez-Sandoval et al., 2011; } \\
\text { Kawaguchi, 1997; Kreitzer, } \\
\text { 2009; Vuillet et al., } 1989\end{array}$ \\
\hline $\begin{array}{l}\text { Low-Threshold Spiking interneurons } \\
\text { (LTS) }\end{array}$ & $\begin{array}{l}\text { Presence of neuropeptide Y, somatostatin and nitric oxide synthase. } \\
\text { Contain few dendritic branches and extensive, but low axonal } \\
\text { arborisation. } \\
\text { High input resistance and a sustained plateau potential that persists } \\
\text { after the end of current injection; rebound spiking following hyper } \\
\text { polarizations. } \\
\text { Synapse with MSNs dendrites. }\end{array}$ & $\begin{array}{l}<10 \% \mathrm{D} 1 \mathrm{R} \\
>70 \% \mathrm{D} 5 \mathrm{R}\end{array}$ & $\begin{array}{l}\text { Ibáñez-Sandoval et al., 2011; } \\
\text { Kawaguchi, 1997; Kreitzer, } \\
\text { 2009; Vuillet et al., } 1989\end{array}$ \\
\hline TH interneurons & $\begin{array}{l}\text { Presence of tyrosine hydroxylase, but do not seem to produce } \\
\text { dopamine. } \\
\text { Medium sized interneurons with low branching, varicose dendrites; } \\
\text { dense, highly varicose axon collateral fields. } \\
\text { Comprise four electrophysiologically distinct neuron types - large } \\
\text { variability. } \\
\text { Make afferent and efferent GABAergic synaptic connections with } \\
\text { MSNs. }\end{array}$ & ? & $\begin{array}{l}\text { Ibáñez-Sandoval et al., 2015, } \\
2010\end{array}$ \\
\hline CR interneurons & $\begin{array}{l}\text { Presence of calretinin. } \\
\text { Medium sized, possess few, aspiny, infrequently branching dendrites. } \\
\text { Electrophysiological profile not fully known, but in part similar to LTS } \\
\text { interneurons. } \\
\text { Sparse connections with MSNs. }\end{array}$ & $50 \% \mathrm{D} 5 \mathrm{R}$ & $\begin{array}{l}\text { English et al., 2012; Kreitzer, } \\
\text { 2009; Tepper and Bolam, } 2004\end{array}$ \\
\hline \multicolumn{4}{|l|}{ Cholinergic interneurons $(0.5-1 \%)$} \\
\hline Cholinergic interneurons (CIN) & $\begin{array}{l}\text { Presence of acetylcholine markers. } \\
\text { Aspiny neurons with large cell bodies and widespread axonal fields. } \\
\text { Hyperpolarization-activated current and broad spikes with long spike } \\
\text { after hyper polarizations; tonic low-frequency activity. } \\
\text { Synapse onto MSNs. }\end{array}$ & $\begin{array}{l}<20 \% \text { D1R; }>80 \% \\
\text { D2R; >80\% D5R }\end{array}$ & $\begin{array}{l}\text { Aosaki et al., 1994; Kreitzer, } \\
\text { 2009; Morris et al., 2004; } \\
\text { Tepper and Bolam, 2004; } \\
\text { Witten et al., 2010; Kaneko } \\
\text { et al., 2000; Hikida et al., } 2001\end{array}$ \\
\hline
\end{tabular}

D1Rs stimulate the heteromeric GPCRs Gs/olf, which are coupled to adenylyl cyclase (AC) (Hervé et al., 1995) (Fig. 3A). The increase in cytosolic cyclic adenosine monophosphate (cAMP) levels causes activation of protein kinase A (PKA) and phosphorylation of its intracellular targets, such as voltage gated $\mathrm{K}^{+}, \mathrm{Na}^{+}$and $\mathrm{Ca}^{2+}$ channels, ionotropic glutamate, GABA receptors and various transcription factors. One of the major targets of PKA is the dopamine and CAMP-regulated phosphoprotein DARPP-32, which is highly expressed in striatal neurons and plays a critical role in the modulation of downstream signals. DARPP-32 can integrate signals from different neurotransmitters and bidirectionally modulate PKA. If PKA phosphorylates DARPP-32 this will amplify PKA signalling by inhibiting protein phosphatase 1 (PP1), which counteracts PKA's activity (Svenningsson et al., 2004). On the other hand, dephosphorylating of DARPP-32 by the calmodulin-dependent protein phosphatase 2B (PP2B), upon D2R-like receptor activation, will convert DARPP-32 into a potent PKA signalling inhibitor and so, completely change neuronal function (Svenningsson et al., 2004). PKA activation, through D1Rs, enhances surface expression of both AMPA and NMDA receptors (Hallett et al., 2006; Snyder et al., 2000). Furthermore, D1R signalled PKA phosphorylation of the somatic Nav1.1 $\mathrm{Na}^{+}$channels promotes activity-dependent entry into an inactivated state (Carr et al., 2003; Scheuer and Catterall, 2006). D1R stimulation is also responsible for inactivation of several $\mathrm{K}^{+}$channels (e.g. Kirk2, Kv1 and Kv4) (Hernandez-Lopez et al., 2000). PKA phosphorylation followed by D1R activation enhances the opening of some $\mathrm{Ca}^{2+}$ channels (e.g. $\mathrm{Ca}_{\mathrm{v}} 1.3$ ), but it reduces the opening of others (e.g. $\mathrm{Ca}_{\mathrm{v}} 2 \mathrm{Ca}^{2+}$ ) (Surmeier et al., 1995; Vilchis et al., 2000). In summary, D1R signalling increases the responsiveness of striatonigral neurons to sustained release of glutamate, by enhancing surface expression of its receptors and by modulating ion channel function to promote MSN up state reviewed in (Surmeier et al., 2007). 
A

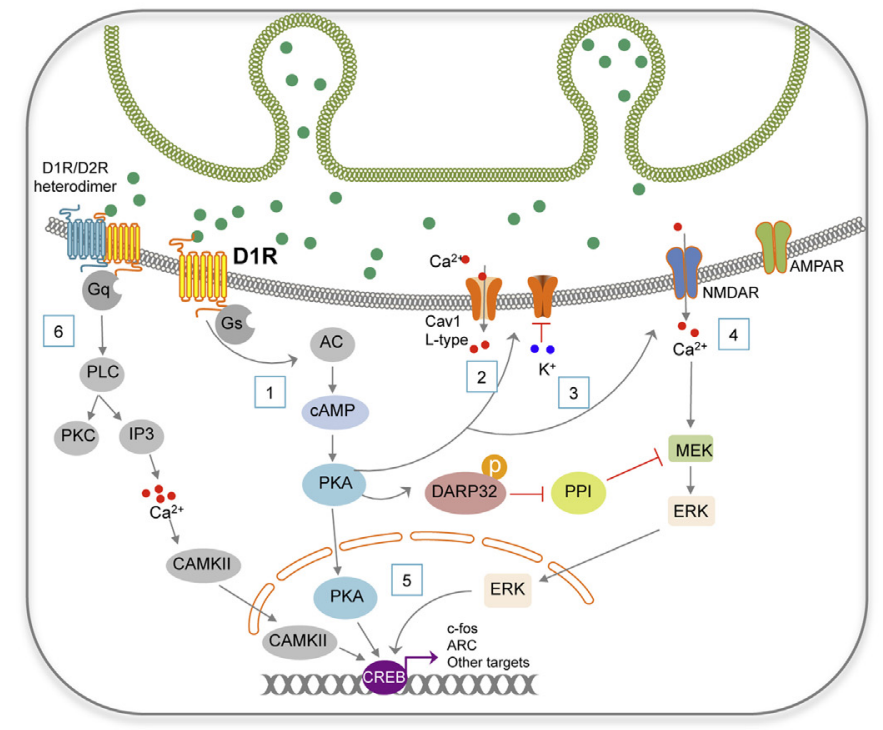

B

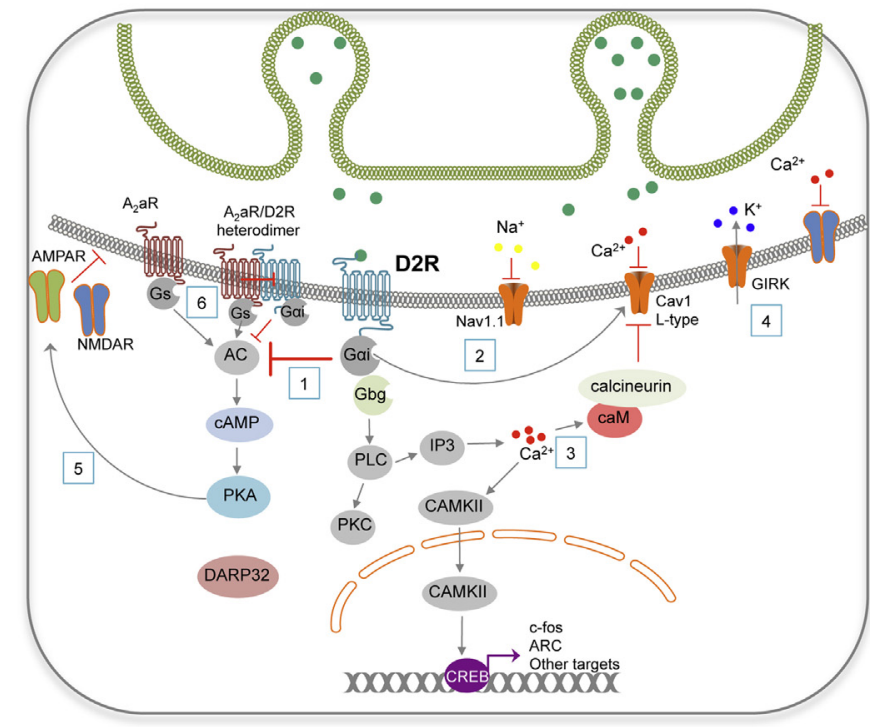

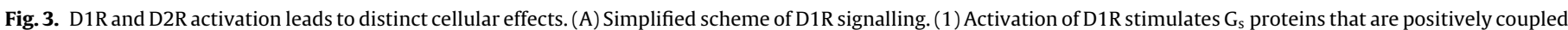

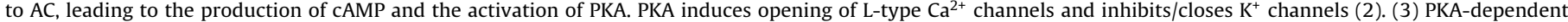

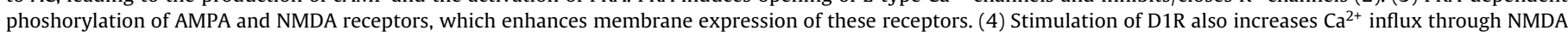

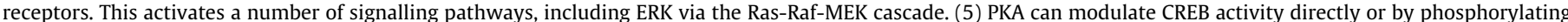

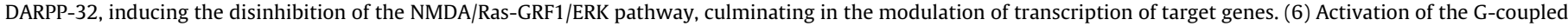

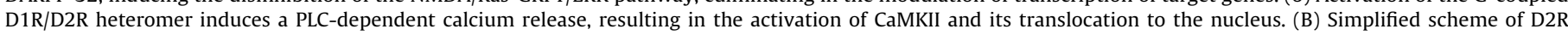

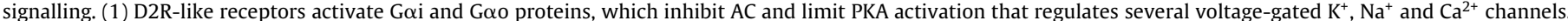

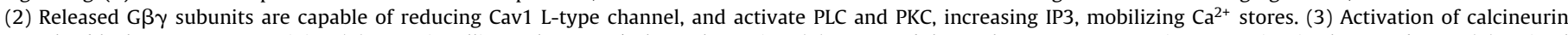

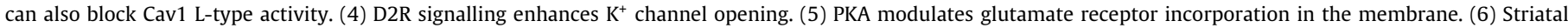

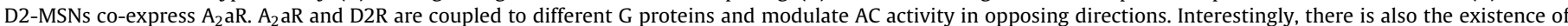

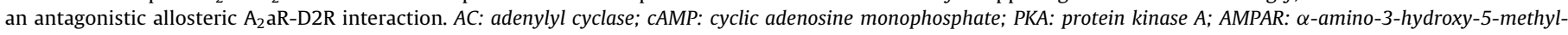

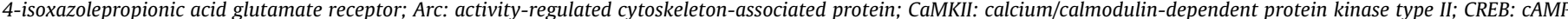

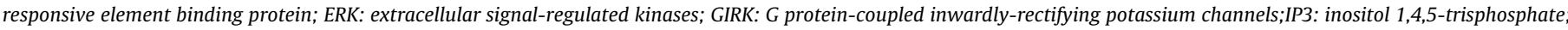

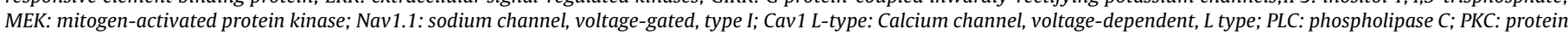

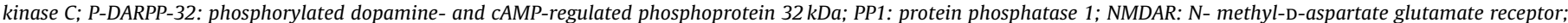
PLC: phospholipase C; IP3: inositol (1,4,5)-trisphosphate; D1R: dopamine receptor 1; D2R: dopamine receptor 2; $A_{2}$ aR: adenosine receptor 2a.

D2Rs are coupled to Gi/o proteins, inhibiting AC and limiting PKA activity (Stoof and Kebabian, 1984) (Fig. 3B). Additionally, $\mathrm{D} 2 \mathrm{R}$ activation is also responsible for the transactivation of tyrosine kinases (TK) (Nair and Sealfon, 2003). Similarly to what occurs with D1R, D2R signalling alters glutamate receptor function in dorsal striatum MSNs, through dephosphorylation of GluR1 subunit that will promote the removal of AMPA receptors from the plasma membrane (Håkansson et al., 2006). D2R-mediated recruitment of intracellular $\mathrm{Ca}^{2+}$ leads to negative modulation of $\mathrm{Ca}_{\mathrm{v}} 1.3 \mathrm{Ca}^{2+}$ channels through calcineurin-dependent mechanism (HernandezLopez et al., 2000; Olson et al., 2005). Additionally, activation of $\mathrm{D} 2 \mathrm{R}$ receptors reduces the opening of $\mathrm{Na}^{+}$channels, dependently of PKC-mediated enhancement of slow inactivation (Surmeier et al., 1992). Moreover, D2R receptor signalling acts by promoting the opening of $\mathrm{K}^{+}\left(\mathrm{K}_{\mathrm{ir}} 3\right)$ channels (Greif et al., 1995), which will change the electrophysiological properties of neurons and generally cause a transient decrease in neuronal excitability (Hernandez-Lopez et al., 2000). In brief, studies are consistent with a role for D2R to reduce the responsiveness of striatopallidal neurons, through coordinated modulation of ion channels function and glutamate receptors expression at the surface.

Importantly, D2Rs are also found presynaptically, where they can modulate neurotransmitter release (Benoit-Marand et al., 2001). In the striatum, D2Rs are present on corticostriatal inputs and function to decrease glutamate release by presynaptic mechanisms (Kornhuber and Kornhuber, 1986; Maura et al., 1988; Yamamoto and Davy, 1992). Additionally, these Gi/o -coupled inhibitory receptors also play a major part in shaping dopamine transmission (Benoit-Marand et al., 2001). Found at both somato- dendritic and axonal sites of the VTA, D2R autoreceptors regulate the firing patterns of dopamine neurons and control the timing and amount of dopamine released within the striatum (Ford, 2014). In addition, D2Rs are also expressed in up to $80 \%$ of CINs (Maurice et al., 2004).

It is important to keep in mind that D2Rs present a mechanism of alternative splicing, and thus, the same gene encodes two distinct isoforms of the same receptor, D2S and D2L (Picetti et al., 1997). Interestingly, these two alternatively spliced receptors have distinct functions in vivo; while D2L acts mainly at postsynaptic sites, D2S serves presynaptic autoreceptor functions (Usiello et al., 2000).

Despite the simplistic vision given above on the mechanism of action of the distinct dopamine receptors within the striatum, it is important also to note that the activity of these receptors goes much beyond the specific activation of its signalling cascades. Although it falls outside the scope of the present review, it is important to keep in mind the existence of interactions between dopamine receptors and other neurotransmitter receptors, known to be relevant for motor control, cognition and memory, neurodegenerative disorders, schizophrenia or even addiction (Calabresi et al., 2000; Chesselet and Delfs, 1996; Fuxe et al., 2010; Graybiel, 1995; Rolls, 1994; Schultz, 1997). Interestingly, these interactions do not occur only at the intracellular level via second messenger pathways, but it also can occur through physical contact. For example, physical contact exists between dopamine receptors and NMDA at the membrane and cytoplasm levels (Freund et al., 1984; Smith and Bolam, 1990). In addition, a direct interaction between the D5R and GABA $A$ receptors has also been reported, which may represent a mechanism controlling synaptic efficacy (Liu et al., 2000). Also, D2R is 
also known to directly interact with $\mathrm{A}_{2} \mathrm{aR}$, converging in the control of AC function (reviewed in Fuxe et al., 2010). In addition to a negative and positive coupling of D2R and $A_{2}$ aR to the adenylate cyclase activity, respectively, there is also an antagonistic allosteric $\mathrm{A}_{2} \mathrm{aR}-\mathrm{D} 2 \mathrm{R}$ interaction (Fig. 3B).

\section{The conundrum: one ligand, different neuronal responses}

In addition to different dopamine receptors that can activate distinctive signalling cascades, in the past years a great deal of attention has been given to the dynamics of striatal dopamine release. Dopaminergic neurons fire in an asynchronous tonic pacemaker manner that can switch to transient synchronous bursts (consisting of a series of consecutive spikes) upon exposure to unexpected or anticipated rewards (Redgrave and Gurney, 2006; Schultz, 2002). Accumulating evidence shows that striatal dopamine neurotransmission occurs in these two dissociable temporal modes, "tonic" and "phasic", both of which are highly regulated by glutamatergic forebrain inputs and by cholinergic and GABAergic inputs within the striatum (Grace, 2000, 1991; Moore et al., 1999).

Tonic dopamine transmission constitutes the extra-synaptic pool of steady-state dopamine levels. These levels are strongly regulated and maintained within a narrow concentration in the striatum (Parsons and Justice, 1992). Phasic dopamine, which is proposed to be the signal that mediates rapid behaviourally relevant activation of the dopamine system by relevant stimuli, is a high-amplitude transient signal that results from a cell-burst firing and consequent uptake of high levels of dopamine by the synapse (Garris et al., 1994).

Phasic dopamine transients that result from synchronous burst firing are mainly thought to activate the low-affinity striatal D1Rs, while tonic dopamine levels arising from pacemaker firing maintain steady-state activation of high-affinity D2Rs (Grace et al., 2007; Grace and Bunney, 1984; Keefe et al., 1993; Richfield et al., 1989; Surmeier et al., 2011). However, recent studies show that highaffinity D2Rs are also activated by phasic dopamine transients (Marcott et al., 2014), which raises new possibilities to the actual contribution of the D2-MSNs pathway in the control of behaviour.

\section{Striatal activity during reward and aversion}

\subsection{Ventral striatum}

Pioneering work by Schultz and colleagues using electrophysiological recordings from the primate striatum revealed excitations in response to cues that predict reward (Bowman et al., 1996; Cromwell and Schultz, 2003; Hassani et al., 2001; Hollerman et al., 1998; Schultz et al., 1997), that depended strongly on the predictive value of the cue (Hassani et al., 2001), the magnitude of the predicted reward (Cromwell and Schultz, 2003), and the temporal proximity to the reward (Shidara et al., 1998). Additionally, it was also shown that the magnitude of the excitation evoked by predictive cues is positively correlated with the motor activity needed to obtain the reward (Cromwell and Schultz, 2003; Hassani et al., 2001; Hollerman et al., 1998). Interestingly, cue-evoked excitation or inhibition of NAc neurons is larger for cues that predict rewards than for cues that do not predict a reward (Ghitza et al., 2003; Nicola, 2007) and larger when the cue elicits a behavioural response (Nicola, 2007).

Intraoral delivery of a sucrose solution increases dopamine release within the NAc, that is time-matched with the infusion onset (Roitman et al., 2005), and NAc neurons respond by decreasing their activity (Roitman et al., 2005). This transient inhibition has also been observed in animals performing behavioral tasks that require operant response like self-administration of many different types of rewarding stimuli such as cocaine (Peoples and West, 1996), heroin (Chang et al., 1998), ethanol (Janak et al., 1999), sucrose (Nicola et al., 2004) and food (Carelli, 2002). On the other hand, oral administration of quinone (an aversive flavor) evokes the opposite response (i.e. suppression of dopamine transients). In addition, NAc neurons are highly responsive to aversive stimuli and respond by increasing their activity (Roitman et al., 2005).

So, in a simplistic perspective, one can assume that rewarding stimuli evoke an instantaneous increase in dopamine release in the NAc and a decrease in the firing rate of NAc neurons. Aversive stimuli evoke the opposite response by suppressing dopamine transients and increasing the firing rate of NAc neurons. Less explored is the role of D1-MSNs and D2-MSNs in this process due to the inherent technical difficulties of separating these populations using in vivo electrophysiological recordings.

\subsection{Dorsal striatum}

Single cell recordings performed in behaving primates showed that dorsal striatal neurons increase activity selectively during the expectation of reward (Apicella et al., 1992; Hikosaka et al., 1989; Schultz et al., 1992; Schultz and Romo, 1988), akin to NAc. Dorsal striatum neurons respond to task-related sensory events by becoming active before task-dependent motor behaviours and maintain a tonic activity until the expected reward is delivered (Hikosaka et al., 1989; Hollerman et al., 1998). Interestingly, the activity of these neurons is modulated by the expected presence, amount or probability of reward or by the amount of attention or memory required to execute the task (Cromwell and Schultz, 2003; Kawagoe et al., 1998). Thus, the presence of sensorimotor, cognitive and motivational signals in single striatal neurons further supports a prominent role of dorsal striatum in learning (Balleine et al., 2007).

Other studies showed that dorsal caudate neurons are activated when different food rewards are shown to the animal (Nishino et al., 1984). Interestingly, this study showed that different neuronal population of the caudate responded to visual presentation of foodand non-food-associated cues and the magnitude of electrophysiological responses was dependent on the nature of the food and was inversely related to the latency of the onset of lever pressing (Nishino et al., 1984). In addition, other neuronal populations also responded during lever pressing and during food retrieval and consumption, thus suggesting that the primate dorsal striatum is constituted by a complex neuronal network that controls sensory, non-motor and motor responses in operant-dependent rewarding events (Nishino et al., 1984). In addition, in a task where a drop of liquid was given each time the animal correctly executed or withheld an arm movement in reaction to a visual stimulus (Go/No-Go task) it was shown that neurons of the dorsal striatum increased activity upon liquid delivery (Apicella et al., 1991), supporting a role in the integration of primary reward information (Apicella et al., 1992, 1991). Additionally, rodents performing a multiple T-maze task with the goal of finding the correct locations to obtain a food reward increase striatal electrical responses not only during motor behaviour, but also during the delivery of food (Schmitzer-Torbert and Redish, 2004).

Apart from reward expectation and consumption, dorsal striatal neurons play a crucial role in decision-making processes, particularly those encoding specific action-outcome associations and the selection of actions on the basis of their currently expected reward value (Gremel and Costa, 2013; Kimchi et al., 2009; Miyachi et al., 2002; Tang et al., 2007). Whereas DMS neurons seem to be crucial in the early acquisition and performance of an instrumental task to receive a reward, i.e., goal-directed behaviour, DLS neurons appear to be preferentially recruited in habitual behaviours that appear 
after overtraining (Gremel and Costa, 2013; Kimchi et al., 2009; Miyachi et al., 2002; Tang et al., 2007).

To what concerns neuronal activity of the dorsal striatum in aversive behaviour in freely moving animals, we did not find any study. Nevertheless, it is important to refer that the SN, which densely innervates dorsal striatum, is not commonly recruited or inhibited by aversive stimuli (Brown et al., 2009), though lesions of dorsal striatum have been shown to produce deficits in conditioned freezing and passive and active avoidance (White and Salinas, 2003; Winocur and Mills, 1969).

Promising tools such as in vivo calcium imaging may shed some light on the activity of different striatal populations in reward and aversion. For example, by using a Cre-dependent viral expression of the calcium indicator GCaMP3 in the dorsal striatum of D1-Cre and $\mathrm{A}_{2} \mathrm{a}$-Cre $\left(\mathrm{A}_{2} \mathrm{aR}\right.$ is co-expressed with D2R) mice, researchers showed that both neuronal populations were activated when animals initiated actions but not in inactive periods (Cui et al., 2013). By using microprobe optical imaging to assess the dynamic changes in intracellular calcium, researchers have shown that cocaine-rewarding effects induce activation of direct-pathway neurons and a slower deactivation of indirect-pathway neurons (Luo et al., 2011).

\section{Role of D1- and D2-MSNs in reward and aversion}

Despite the known cytoarchitecture of the striatum, its heterogeneity poses a major challenge for the attribution of specific biological roles to each type of MSN in behaviour. Traditionally, D1MSNs are thought to mediate reward and positive reinforcement whereas D2-MSNs encode aversion and negative reinforcement (Kravitz et al., 2012; Lobo et al., 2010; Volman et al., 2013); however, some recent data challenges this simple dichotomy (Cazorla et al., 2014; Kupchik et al., 2015; Saunders et al., 2015; Smith et al., 2013; Soares-Cunha et al., 2016).

Having this in mind, in the following sections, we will discuss pharmacological, genetic and optogenetic studies that have been applied to try to clarify the biological role of each type of MSN in reward and in aversion, and highlight the differences between dorsal striatum and ventral striatum neuronal populations in the modulation of these behaviours.

\subsection{Pharmacological approaches}

Initial pharmacological manipulations using selective agonists and antagonists allowed a breakthrough in the understanding of the role of D1R and D2R in reward and, less so, in aversive behaviors. Because systemic administration of these compounds challenges the interpretation of the data, in this review we will only focus on intra-striatal administration of D1R and D2R agonists/antagonists.

\subsubsection{NAC D1R and D2R in reward/reinforcement}

Different groups showed that NAc local application of both D1R and D2R agonists stimulated locomotor activity (Breese et al., 1987; Dreher and Jackson, 1989; Fink et al., 1991). Regarding reward/reinforcement, the literature is inconsistent. Initial studies have shown that NAc administration of D1R and D2R agonists is reinforcing (White et al., 1991). Conversely, others have shown that intra-accumbal administration of D1R or D2R agonists is not reinforcing per se, because animals do not readily self-administer these compounds. However, concurrent activation of both D1R and D2R in the NAc shell had a cooperative effect, inducing self-administration (Ikemoto et al., 1997). In accordance, recent studies have shown that both D1R and D2R in the NAc are required for mediating the reinforcing properties of optogenetic self-stimulation of VTA-NAc projections (Steinberg et al., 2014).

Regarding the effects of these receptors in mediating natural reward-related responses, it was shown that in hungry rats, pharmacological blockade of D1Rs or D2Rs in the NAc affects the amount and duration of feeding, but it does not reduce the amount of food consumed (Baldo et al., 2002). In agreement, others have shown that blockade of D1Rs or D2Rs within the NAc core or shell decreased lever pressing for food reinforcers, but rats remained directed towards the acquisition and consumption of food (Nowend et al., 2001). This data indicates that both D1R and D2R signalling are relevant for the motivational drive to work to get a food pellet. In fact, using a Pavlovian-to-Instrumental-transfer test (PIT), which indirectly measures "wanting"/incentive salience, it was shown that selective D1R and D2R blockade in the NAc reduced performance (Dickinson et al., 2000; Lex and Hauber, 2008). In accordance, we have shown that D2R dysfunction within the NAc impairs PIT performance, and that systemic administration of a D2R agonists improved behaviour (Soares-Cunha et al., 2014). In agreement, others have shown that microinjection of D1R or D2R antagonists into the NAc reduce the proportion of cues to which the animal responded to get a food pellet (Wakabayashi et al., 2004). Effort-related choice tests also revealed that effort discounting (an indirect measure of motivation) was altered by administration of D2R antagonists, shifting the choice towards the low reinforcement/low cost arm and this was reverted by increased dopamine transmission (Nunes et al., 2010).

Pharmacological targeting of NAc D1R and D2R signaling has also been used to tackle the role of these neurons in the response to drugs of abuse. Most of the studies point for a prorewarding/reinforcing role of $\mathrm{D} 1 \mathrm{R}$ and a null or attenuating effect of D2Rs. For example, rodents pre-treated with a D1R (but not D2R) antagonist showed an attenuated locomotor response to acute cocaine challenge (Anderson et al., 2003), and intra-accumbal administration of D1R antagonist prevents cocaine (Baker et al., 1998) and ethanol place preference (Pina and Cunningham, 2014; Young et al., 2014). On the contrary, others have shown that both D1R and D2R antagonists significantly block the development of amphetamine place preference (Liao, 2008). Later studies have suggested that activation of accumbal D2Rs does not cause primary rewarding effects, but it can facilitate the previous associated rewarding effects of environmental stimuli (Nunes et al., 2010; Self, 2010). In fact, administration of D2R agonists has prominent reinforcing and enhancing effects in cocaine self-administration in animals with extensive experience in this behaviour (Caine et al., 2002). Interestingly, the observed discrepancies in the studies may be related to drug-specific effects, the use of different dosages of antagonists, subtle differences in the behavioural paradigms or a result of the complex distribution of D2R.

\subsection{2. $N A C D 1 R$ and $D 2 R$ in aversion}

The literature is sparser regarding the role of accumbal D1R and D2R antagonists in aversion. An aversive event induces a negative hedonic state; however, due to technical limitations in evaluating the hedonic state of animals, researchers frequently use avoidance behaviour as a representation of aversion (Kravitz and Kreitzer, 2012). Using the two-way active avoidance task, researchers showed that D2R antagonist infusion into the NAc (but not in dorsal striatum) slightly decreased the number of conditioned avoidance responses (Boschen et al., 2011); a similar effect was observed with D1R antagonists (Wietzikoski et al., 2012). Such effects may be partially due to the D1R and D2R contribution for early consolidation of aversive memory (Managò et al., 2009).

\subsubsection{Dorsal striatum $D 1 R$ and $D 2 R$ in reward and aversion}

Studies evaluating the impact of local dorsal striatum pharmacological inhibition/activation of $\mathrm{D} 1 \mathrm{R} / \mathrm{D} 2 \mathrm{R}$ in reward and aversion are limited. In primates, D1R antagonism in the caudate nucleus (dorsal striatum part in primates) attenuated the rewarddependent saccadic reaction time changes, in contrast to what was 
found with D2R antagonism (Nakamura and Hikosaka, 2006). On the contrary, expression of amphetamine place preference is not blocked by infusion in the dorsal striatum of D1R and D2R antagonists (Hiroi and White, 1991). Regarding aversion, as stated before, dorsal striatum D2R antagonism did not impact the number of conditioned avoidance responses (Boschen et al., 2011).

Altogether, these studies seem to indicate that NAc D1R pathway promotes reward/reinforcement whereas D2R signalling has an opposing effect, although disparate results have also been found. Nevertheless it is important to refer that pharmacological activation/inactivation of D1R or D2R is not a direct proxy of D1-MSN or D2-MSN activation/inactivation. In addition, the use of agonists/antagonists raises different questions: (i) the existence of $\mathrm{D} 1^{+} / \mathrm{D} 2^{+}$-MSNs is not taken into consideration, (ii) other types of striatal cells namely interneurons also possess D1R and D2R, (iii) the existence of pre-synaptic D2Rs in dopaminergic terminals that strongly modulate striatal neuronal activity, (iv) drugs are rarely specific to one type of receptor, ( $v$ ) pharmacological approaches have poor temporal resolution and diffusion to other brain regions can occur, challenging the interpretation of the data. Such limitations triggered other approaches to elucidate these questions that we will discuss in the next sections.

\subsection{Genetic models}

The use of genetic methods can provide an alternative for understanding the importance of a specific receptor/pathway. However, it also poses some problems: conventional knockouts often present compensatory mechanisms, and the deletion of D1R or D2R throughout the brain defies the identification of the biological role of striatal neurons per se in behavior. Later studies include specific striatal ablation of these receptors, providing a more elegant approach.

\subsubsection{D1R knockout models and reward/reinforcement}

The first constitutive D1R knockout (KO) transgenic mice lines were obtained by deletion of either part (Drago et al., 1996) or most of the D1R coding region (Xu et al., 1994) of the genome. D1R KO mice have abnormal locomotor behaviour that ranges from hypoactive to hyperactive depending on the experimental conditions. Although in several studies it was reported that these mice were hyperactive in a novel environment and during the dark phase of the light-dark cycle (Granado et al., 2008; Xu et al., 1994), others reported an increased latency to move in an open field consistent with a hypoactive phenotype (Smith et al., 1998).

Although these animals failed to feed normally after weaning (Wall et al., 2011), this phenotype could be rescued by providing $\mathrm{KO}$ mice free access to a palatable food, suggesting that the absence of $\mathrm{D} 1 \mathrm{R}$ is more related to a motor deficit than to a reward deficit (Drago et al., 1994; Xu et al., 1994). However, more recent studies showed that D1R KO animals present greatly reduced motivation to work for a food reward in a sucrose preference test, which demonstrates that dopamine signalling through D1R-expressing neurons possibly plays an important role in the modulation of motivational processing (El-Ghundi et al., 2003; Gallardo et al., 2014). D1R KO mice also failed to perform a Pavlovian conditioning task (Parker et al., 2010).

The response to drugs of abuse is also compromised in D1R KO animals (nicely reviewed in Lobo and Nestler, 2011). D1R KO mice performing a cocaine self-administration task presented decreased preference for the active lever and reduced overall responses (Caine et al., 2007). These animals also present diminished ethanol consumption (El-Ghundi et al., 1998).

\subsubsection{D2R knockout models and reward/reinforcement}

Constitutive D2R KO mice display decreased body weight and reduced spontaneous locomotion (Baik et al., 1995; Kobayashi et al., 2004; Nakamura et al., 2014). These animals also respond less for food rewards in instrumental tasks, which could either be attributed to their hypolocomotion or to impairment in motivated responses (Risinger et al., 2000).

The effects of D2R deletion in the response to drugs of abuse resemble those for natural rewards. D2R KO have blunted response to the rewarding (Maldonado et al., 1997) and reinforcing properties of morphine (Elmer et al., 2002), ethanol (Cunningham et al., 2000) and cocaine (Welter et al., 2007).

Other genetic studies have targeted different aspects of D2MSNs intracellular signaling. Lobo and co-workers knocked down expression of the sphingosine-1-phosphate receptor Gpr6 (which can stimulate cAMP production-in opposition to D2R activation) in striatopallidal cells (indirect pathway) (Lobo et al., 2007). These animals have a faster acquisition of operant lever pressing for sugar pellets, suggesting enhanced motivation in a situation that partially mimics increased D2R activity (Lobo et al., 2007). Also, overexpression of D2R in the NAc using viral gene transfer, selectively increased motivation for food (in a progressive ratio schedule) without altering consummatory behaviour, the representation of the value of the reinforcer, or the capacity to use reward-associated cues in flexible ways, contrary to dorsal striatum D2R overexpression which did not alter performance in any of the tasks (Trifilieff et al., 2013).

\subsubsection{D1R and D2R knockout models and aversion}

A few studies have focused on the role of D1R and D2R neurons in aversion. It has been reported that D1R ablation (using constitutive D1R KO mice) prevented the expression of conditioned aversive stimuli, which may indicate that D1R activation is also required for the acquisition and expression of taste aversion learning (Cannon et al., 2005). A mice model lacking D2L (post-synaptic) but expressing functional D2S, developed place preference to cocaine (but not morphine), and did not acquire place aversion to morphine withdrawal. These animals also failed to acquire avoidance behavior in response to electrical stimuli (Smith et al., 2002).

In summary, data from genetic models suggest that whereas the response to natural rewards appears to be modulated by both types of receptors in a similar/synergistic manner, the same does not seem to be true regarding drugs of abuse, with D1R promoting reward and sensitizing responses to psychostimulants and D2R dampening these behaviors. This paradoxical finding is far from being understood and highlights the importance of distinguish natural vs non-natural rewards and associated responses. Regarding aversion, the few studies seem to pinpoint a predominant role for D2Rs in aversive learning.

\subsection{Specific striatal manipulations}

An elegant approach using a reversible neurotransmission blocking technique has shown that the striatonigral pathway is critical for reward learning whereas the striatopallidal pathway was important aversive learning (Hikida et al., 2010). Later, these researchers have combined this methodology with local infusion of a receptor-specific agonist or antagonist in the NAc. They showed that bilateral blockade of the direct pathway in the NAc, but not that of the indirect pathway, significantly reduced cocaine-induced place preference and decreased expression of appetitive reward learning. In addition, mice lacking the D2L receptors (postsynaptic) present a significant impairment in aversive learning (Hikida et al., 2013). Interestingly, this data was supported by the fact that specific inhibition of D2R-dependent neurotransmission within the 
NAc also causes impairment in aversive learning in a one-trial inhibitory avoidance task (Hikida et al., 2013).

Others have shown that ablation of NAc $\mathrm{A}_{2}$ aR-expressing neurons ( $A_{2} a R$ is co-expressed with $D 2 R$ receptor in striatum) induced an increase in amphetamine conditioned place preference, suggesting that these neurons inhibit drug reinforcement (Durieux et al., 2009).

\subsection{Pharmacogenetic studies}

Recent studies used viral-mediated expression of a designer receptor exclusively activated by a synthetic drug (DREADDs); activation the DREADD hM4D receptor potently reduces striatal excitability. With this technique, researchers found that transient disruption of striatopallidal (D2R) neuronal activity facilitated behavioural sensitization to amphetamine, whereas decreasing excitability of striatonigral (D1R) neurons impaired its persistence (Ferguson et al., 2011).

\subsection{Optogenetic studies}

Optogenetic studies have provided an elegant tool to manipulate different populations of striatal neurons in a fast, specific and reversible manner in order to overcome some caveats of earlier studies. However, the use of these tools also present clear limitations: (i) viral expression of opsins relies on the use of specific promoters that sometimes are not fully characterized, (ii) different stimulation protocols may activate/inhibit distinctive neuronal populations, leading to idiosyncratic behavioral outcomes (this is particularly important considering the unique roles of phasic vs tonic dopamine signaling), (iii) the use of transgenic cre strains to drive opsin expression may present ectopic expression of cre protein (Gong et al., 2007; Stuber et al., 2015) and last, but not least, (iv) optical neuronal activation does not necessarily mimic physiological activity.

\subsubsection{Optogenetic activation of D1-MSNs: NAc versus dorsal} striatum

Most of the studies use cre-dependent opsins packed in viral particles in combination with cre transgenic models. Optogenetic stimulation of D1-MSNs within the NAc does not have a major effect on locomotor activity (Francis et al., 2015; Soares-Cunha et al., 2016), and is sufficient to increase the willingness to work for food (Soares-Cunha et al., 2016), suggesting a pro-reward role. This is in line with studies indicating that activation of NAc D1-MSNs is sufficient to increase cocaine sensitization and cocaine place preference (Lobo et al., 2010). In agreement, optogenetic inactivation of D1-MSNs supresses cocaine sensitization (Chandra et al., 2013).

Contrary to NAc, activation of D1-MSNs in the dorsal striatum increased spontaneous locomotion as expected. Dorsal striatum D1-MSNs activation was sufficient to induce an operant behaviour in order to receive optic stimulation of these neurons, which confirms its reinforcing properties (Kravitz et al., 2010). Others have shown that unilateral stimulation of D1-MSNs shifts responses for reward toward the contralateral side of the stimulation (Tai et al., 2012). The authors attributed this bias to the positive effects of activation of the direct pathways within the dorsal striatum on motivated responses (Tai et al., 2012). Interestingly, stimulation of D1-MSNs of the dorsal striatum also results in an increase in cocaine place conditioning (Kravitz et al., 2012) emphasizing the role of D1MSNs in reinforcement. Recently it was shown that although both activation of D1- and D2-MSNs within the DMS result in increased self-stimulation, optical stimulation of D1-MSNs was shown to be involved with actions that support goal-directed behaviours, while activation of D2-MSNs resulted in actions that support the formation of stimulus-response habits (Vicente et al., 2016).

\subsubsection{Optogenetic activation of D2-MSNs: NAc versus dorsal striatum}

Less concordant is the contribution of NAc D2-MSNs in locomotion, reward and aversion. Activating cre-dependent ChR2 in a D2-cre transgenic mouse line did not trigger a major impact in locomotion (Francis et al., 2015; Lobo et al., 2010), although others reported a decrease in basal locomotor activity (Song et al., 2014).

Stimulation of NAc D2-MSNs attenuated cocaine conditioned place preference (Lobo et al., 2010), and stimulation of $\mathrm{A}_{2} \mathrm{aR}$ containing neurons (supposedly D2-MSNs) and supressed cocaine self-administration (Bock et al., 2013). This anti-reward role was challenged by evidence showing that stimulation of NAc D2-MSNs neither affected the acquisition or expression of cocaine-induced behavioral sensitization (Song et al., 2014). In addition, we have shown that accumbal D2-MSNs stimulation strongly enhances motivation/willingness to work for food and is able to induce place conditioning per se (Soares-Cunha et al., 2016; Soares-Cunha et al., unpublished observations).

Moreover, it was shown that the reinforcing properties of optogenetic activation of VTA-NAc dopaminergic terminals requires both D1-MSNs or D2-MSNs signaling (Steinberg et al., 2014). The discrepancy in the results might be attributed to technical differences in the experimental protocols. However, one cannot exclude that D2-MSNs may contribute differentially to responses to natural rewards and to drugs of abuse, an aspect that needs to be explored in future works.

Less controversy exists regarding the role of dorsal striatum D2-MSNs on motor activity and reward/aversion. As expected, stimulation of dorsal striatum D2-MSNs (using $\mathrm{A}_{2}$ a-cre line) decreases locomotor activity (Kravitz et al., 2012). Importantly, in this same study, it was shown that D2-MSNs activation caused punishment, by inducing a transient period of avoidance towards the trigger that originated D2-MSNs stimulation (Kravitz et al., 2012). Using a D2-cre line, optogenetic stimulation of dorsal striatum D2MSNs neurons shifted operant responses for food rewards toward the ispilateral side of the stimulation, resembling a decrease in the value for the reward (Tai et al., 2012).

In summary, optogenetic studies seem to support the established view of pro-reward role of D1-MSNs both in the ventral striatum and dorsal striatum. Less explicit is the role of D2MSNs in reward and aversion, since conflicting findings have been described, which suggests that further studies are needed to understand the contribution of these MSNs for these behavioural dimensions.

\section{Striatal D1R and D2R in human behavior}

Human imaging studies have also provided some insights on the role of striatal dopaminergic signaling in reward behaviors, namely in the control of motivation, in incentive salience and reinforcement, and to a lesser extent in aversion/punishment.

Similar to findings in animal models, earlier human studies have shown that dopamine is released in the ventral striatum in anticipation to monetary or taste rewards (Knutson et al., 2001; O'Doherty et al., 2002). Later studies have refined the paradigms and were able to show that the striatum responds (albeit differently) to monetary outcomes of different valence (reward and punishment) (Delgado, 2007; Delgado et al., 2000). Interestingly, an anteroposterior valence-specific gradient seems to exist at least in the NAc, with more anterior regions showing relative selectivity for rewards and posterior regions for losses (Seymour et al., 2007). In addition to anatomical specificities, in non-human primates, 
separate neural striatal populations coding for actions that are probabilistically associated with positive and negative outcomes exist (Samejima et al., 2005). Several other works have supported the co-existence of appetitive and aversive prediction-error signals within the dopaminergic mesolimbic system, which shifts the view of the canonical "reward pathway" to a value-based decision making system (reviewed in Brooks and Berns, 2013; Liu et al., 2011).

But how can a single molecule mediate two opposing behaviors? The simplest response points for the selective activation of different dopamine receptors. A current popular model argues that burst (phasic) dopamine signals that encode unexpected rewards are associated with behavioral activation (Go) through D1R (low affinity), whereas aversion/avoidance (No Go) learning is mediated through D2R (high affinity) in a U-shaped manner (Frank et al., 2004). In this perspective, it is interesting that individual differences in human approach and avoidance learning are predicted by variability in striatal D1R and D2R binding, respectively (Cox et al., 2015). Adding further complexity to the interpretation of the findings, it has been shown that striatal (and frontal) asymmetries in D2R binding (rather than absolute binding levels) predict individual differences in learning from reward versus punishment (Tomer et al., 2013). Importantly, in drug abusers, low striatal D2R availability is predictive of a pleasurable response to intravenous stimulant administration, while high binding was associated with an aversive experience (Volkow et al., 2002, 1999). Paradoxical findings have also been found, showing that D2R is decisive for measures of choice performance rather than for aversive instrumental learning (Eisenegger et al., 2014).

Natural genetic variants resulting in either increased (C957T polymorphism) or reduced (A1 alelle) striatal D2R also modulate valenced responses. For example, C957T polymorphism is associated with enhanced learning from negative outcomes (Frank et al., 2007). A1 carriers, (lower striatal D2R expression but increased striatal dopamine), are less successful in predicting negative outcomes and showing diminished recruitment of ventral striatum during negative feedback processing and reversal learning (Jocham et al., 2009; Klein et al., 2007). All of these findings support a bidirectional modulatory role for striatal dopamine in reward - via D1R - and aversion learning - via D2R.

In addition to the prevalent view that (phasic) dopamine encodes prediction error signals that mediate reinforcement learning (Bayer and Glimcher, 2005; Schultz et al., 1997), there is also evidence that (tonic) dopamine may play a role in response vigor and motivational aspects of reinforcement, and this may rely on the activation of different dopamine receptors at the striatum level (Bromberg-Martin et al., 2010; Niv et al., 2006). For example, higher D2R availability in the left striatum is associated with greater positive incentive motivation in healthy controls (Tomer et al., 2008). Both healthy volunteers and schizophrenics treated with atypical neuroleptics showed ventral striatum activation in response to reward-predicting cues; however, in patients treated with typical neuroleptics, which block D2R, this response is blunted and is correlated with motivational deficits and the severity of negative symptoms (Juckel et al., 2006).

\section{Conclusion}

Although different approaches have provided insights about the role of striatal D1-MSNs and D2-MSNs in reward/aversion, the complexity of these behaviors challenges the interpretation of the data. It is remarkably difficult to separate and evaluate distinct aspects of reward/aversion without interference. Moreover, it is important to highlight that clear differences exist between dorsal striatum and NAc MSNs, and the lack of segregation of the direct/indirect pathways based on D1R and D2R expression in the NAc.

Evidence strongly suggests that the canonical view of striatal D1R signalling as pro-reward/reinforcing and D2R signalling as pro-aversive is too simplistic. It is naïve to assume that D1R- and D2R-expressing neurons play completely independent (and contrasting) roles. We believe that there is a coordinated (and not necessarily antagonic) action between the two neuronal subpopulations in the control of these behaviours. Interestingly, some recent studies have also questioned the pro- or anti-kinetic dichotomy of D1-MSNs/direct or D2-MSNs/indirect pathways in motor control (Cui et al., 2013), emphasizing the need to re-evaluate the early view that striatal D1- and D2-MSNs mediate exclusively opposing aspects of behaviour.

\section{Acknowledgments}

CS-C and BC are recipients of Fundação para a Ciência e Tecnologia (FCT) fellowships (SFRH/BD/51992/2012; SFRH/BD/98675/2013). AJR is a FCT investigator (IF/00883/2013). Authors are funded by the Portuguese North Regional Operational Program (ON.2-O Novo Norte) under the National Strategic Reference Framework (QREN), through the European Regional Development Fund (FEDER); and by the Projeto Estratégico - LA 26-2013-2014 (PEst-C/SAU/LA0026/2013).

\section{References}

Al-Hasani, R., McCall, J.G., Shin, G., Gomez, A.M., Schmitz, G.P., Bernardi, J.M., Pyo, C.-O., Park, S.I., Marcinkiewcz, C.M., Crowley, N.A., Krashes, M.J., Lowell, B.B., Kash, T.L., Rogers, J.A., Bruchas, M.R., 2015. Distinct subpopulations of nucleus accumbens dynorphin neurons drive aversion and reward. Neuron 87 , 1063-1077.

Anderson, S.M., Bari, A.A., Pierce, R.C., 2003. Administration of the D1-like dopamine receptor antagonist $\mathrm{SCH}-23390$ into the medial nucleus accumbens shell attenuates cocaine priming-induced reinstatement of drug-seeking behavior in rats. Psychopharmacology (Berl.) 168, 132-138.

Aosaki, T., Tsubokawa, H., Ishida, A., Watanabe, K., Graybiel, A.M., Kimura, M., 1994 Responses of tonically active neurons in the primate's striatum undergo systematic changes during behavioral sensorimotor conditioning. J. Neurosci. 14, 3969-3984.

Apicella, P., Ljungberg, T., Scarnati, E., Schultz, W., 1991. Responses to reward in monkey dorsal and ventral striatum. Exp. Brain Res. 85, 491-500.

Apicella, P., Scarnati, E., Ljungberg, T., Schultz, W., 1992. Neuronal activity in monkey striatum related to the expectation of predictable environmental events. J. Neurophysiol. 68, 945-960.

Baik, J.H., Picetti, R., Saiardi, A., Thiriet, G., Dierich, A., Depaulis, A., Le Meur, M., Borrelli, E., 1995. Parkinsonian-like locomotor impairment in mice lacking dopamine D2 receptors. Nature 377, 424-428.

Baker, D.A., Fuchs, R.A., Specio, S.E., Khroyan, T.V., Neisewander, J.L., 1998. Effects of intraaccumbens administration of SCH-23390 on cocaine-induced locomotion and conditioned place preference. Synapse 30, 181-193, N. Y. N.

Baldo, B.A., Sadeghian, K., Basso, A.M., Kelley, A.E., 2002. Effects of selective dopamine D1 or D2 receptor blockade within nucleus accumbens subregions on ingestive behavior and associated motor activity. Behav. Brain Res 137 , $165-177$.

Balleine, B.W., Delgado, M.R., Hikosaka, O., 2007. The role of the dorsal striatum in reward and decision-making. J. Neurosci. 27, 8161-8165.

Baumann, B., Danos, P., Krell, D., Diekmann, S., Leschinger, A., Stauch, R., Wurthmann, C., Bernstein, H.G., Bogerts, B., 1999. Reduced volume of limbic system-affiliated basal ganglia in mood disorders: preliminary data from a postmortem study. J. Neuropsychiatry Clin. Neurosci. 11, 71-78.

Bayer, H.M., Glimcher, P.W., 2005. Midbrain dopamine neurons encode a quantitative reward prediction error signal. Neuron 47, 129-141.

Beaulieu, J.-M., Gainetdinov, R.R., 2011. The physiology, signaling, and pharmacology of dopamine receptors. Pharmacol. Rev. 63, 182-217.

Bennett, B.D., Bolam, J.P., 1994. Synaptic input and output of parvalbumin-immunoreactive neurons in the neostriatum of the rat. Neuroscience 62, 707-719.

Benoit-Marand, M., Borrelli, E., Gonon, F., 2001. Inhibition of dopamine release via presynaptic D2 receptors: time course and functional characteristics in vivo. J. Neurosci. 21, 9134-9141.

Berendse, H.W., Galis-de Graaf, Y., Groenewegen, H.J., 1992. Topographical organization and relationship with ventral striatal compartments of prefrontal corticostriatal projections in the rat. J. Comp. Neurol. 316, 314-347.

Bertran-Gonzalez, J., Bosch, C., Maroteaux, M., Matamales, M., Hervé, D., Valjent, E., Girault, J.-A., 2008. Opposing patterns of signaling activation in dopamine D1 
and D2 receptor-expressing striatal neurons in response to cocaine and haloperidol. J. Neurosci. 28, 5671-5685.

Bevan, M.D., Booth, P.A., Eaton, S.A., Bolam, J.P., 1998. Selective innervation of neostriatal interneurons by a subclass of neuron in the globus pallidus of the rat. J. Neurosci. 18, 9438-9452.

Bjorklund, A., Hokfelt, T., Swanson, L.W., 1996. Integrated Systems of the CNS, Part III: Cerebellum, Basal Ganglia Olfactory System. Elsevier.

Bock, R., Shin, J.H., Kaplan, A.R., Dobi, A., Markey, E., Kramer, P.F., Gremel, C.M., Christensen, C.H., Adrover, M.F., Alvarez, V.A., 2013. Strengthening the accumbal indirect pathway promotes resilience to compulsive cocaine use. Nat. Neurosci. 16, 632-638.

Bolam, J.P., Ingham, C.A., Izzo, P.N., Levey, A.I., Rye, D.B., Smith, A.D., Wainer, B.H., 1986. Substance P-containing terminals in synaptic contact with cholinergic neurons in the neostriatum and basal forebrain: a double immunocytochemical study in the rat. Brain Res. 397, 279-289.

Boschen, S.L., Wietzikoski, E.C., Winn, P., Da Cunha, C., 2011. The role of nucleus accumbens and dorsolateral striatal D2 receptors in active avoidance conditioning. Neurobiol. Learn. Mem. 96, 254-262.

Bowman, E.M., Aigner, T.G., Richmond, B.J., 1996. Neural signals in the monkey ventral striatum related to motivation for juice and cocaine rewards. J. Neurophysiol. 75, 1061-1073.

Breese, G.R., Duncan, G.E., Napier, T.C., Bondy, S.C., Iorio, L.C., Mueller, R.A., 1987. 6-Hydroxydopamine treatments enhance behavioral responses to intracerebral microinjection of D1- and D2-dopamine agonists into nucleus accumbens and striatum without changing dopamine antagonist binding. J. Pharmacol. Exp. Ther. 240, 167-176.

Bromberg-Martin, E.S., Matsumoto, M., Hikosaka, O., 2010. Dopamine in motivational control: rewarding, aversive, and alerting. Neuron 68, 815-834.

Brooks, A.M., Berns, G.S., 2013. Aversive stimuli and loss in the mesocorticolimbic dopamine system. Trends Cogn. Sci. 17, 281-286.

Brown, M.T.C., Henny, P., Bolam, J.P., Magill, P.J., 2009. Activity of neurochemically heterogeneous dopaminergic neurons in the substantia nigra during spontaneous and driven changes in brain state. J. Neurosci. 29, 2915-2925.

Cachope, R., Mateo, Y., Mathur, B.N., Irving, J., Wang, H.-L., Morales, M., Lovinger, D.M., Cheer, J.F., 2012. Selective activation of cholinergic interneurons enhances accumbal phasic dopamine release: setting the tone for reward processing. Cell Rep. 2, 33-41.

Caine, S.B., Negus, S.S., Mello, N.K., Patel, S., Bristow, L., Kulagowski, J., Vallone, D., Saiardi, A., Borrelli, E., 2002. Role of dopamine D2-like receptors in cocaine self-administration: studies with D2 receptor mutant mice and novel D2 receptor antagonists. J. Neurosci. 22, 2977-2988 (20026264).

Caine, S.B., Thomsen, M., Gabriel, K.I., Berkowitz, J.S., Gold, L.H., Koob, G.F., Tonegawa, S., Zhang, J., Xu, M., 2007. Lack of self-administration of cocaine in dopamine D1 receptor knock-out mice. J. Neurosci. 27, 13140-13150.

Calabresi, P., Centonze, D., Gubellini, P., Marfia, G.A., Pisani, A., Sancesario, G., Bernardi, G., 2000. Synaptic transmission in the striatum: from plasticity to neurodegeneration. Prog. Neurobiol 61, 231-265.

Cannon, C.M., Scannell, C.A., Palmiter, R.D., 2005. Mice lacking dopamine D1 receptors express normal lithium chloride-induced conditioned taste aversion for salt but not sucrose. Eur. J. Neurosci. 21, 2600-2604.

Carelli, R.M., 2002. Nucleus accumbens cell firing during goal-directed behaviors for cocaine vs natural reinforcement. Physiol. Behav. 76, 379-387.

Carr, D.B., Day, M., Cantrell, A.R., Held, J., Scheuer, T., Catterall, W.A., Surmeier, D.J., 2003. Transmitter modulation of slow, activity-dependent alterations in sodium channel availability endows neurons with a novel form of cellular plasticity. Neuron 39, 793-806.

Cazorla, M., de Carvalho, F.D., Chohan, M.O., Shegda, M., Chuhma, N., Rayport, S., Ahmari, S.E., Moore, H., Kellendonk, C., 2014. Dopamine D2 receptors regulate the anatomical and functional balance of basal ganglia circuitry. Neuron 81 , $153-164$.

Centonze, D., Grande, C., Usiello, A., Gubellini, P., Erbs, E., Martin, A.B., Pisani, A., Tognazzi, N., Bernardi, G., Moratalla, R., Borrelli, E., Calabresi, P., 2003. Receptor subtypes involved in the presynaptic and postsynaptic actions of dopamine on striatal interneurons. J. Neurosci. 23, 6245-6254.

Cepeda, C., André, V.M., Yamazaki, I., Wu, N., Kleiman-Weiner, M., Levine, M.S., 2008. Differential electrophysiological properties of dopamine D1 and D2 receptor-containing striatal medium-sized spiny neurons. Eur. J. Neurosci. 27, 671-682.

Chandra, R., Lenz, J.D., Gancarz, A.M., Chaudhury, D., Schroeder, G.L., Han, M.-H., Cheer, J.F., Dietz, D.M., Lobo, M.K., 2013. Optogenetic inhibition of D1R containing nucleus accumbens neurons alters cocaine-mediated regulation of Tiam1. Front. Mol. Neurosci. 6, 13.

Chang, J.-Y., Janak, P.H., Woodward, D.J., 1998. Comparison of mesocorticolimbic neuronal responses during cocaine and heroin self-administration in freely moving rats. J. Neurosci. 18, 3098-3115.

Charara, A., Sidibé, M., Smith, Y., 2003. Basal ganglia circuitry and synaptic connectivity. In: T, D., v, J.L., L, A.M. (Eds.), Surgical Treatment of Parkinson's Disease and Other Movement Disorders, Current Clinical Neurology. Humana Press, pp. 19-39.

Chesselet, M.F., Delfs, J.M., 1996. Basal ganglia and movement disorders: an update. Trends Neurosci. 19, 417-422.

Choi, W.Y., Morvan, C., Balsam, P.D., Horvitz, J.C., 2009. Dopamine D1 and D2 antagonist effects on response likelihood and duration. Behav. Neurosci. 123, 1279-1287.
Cox, S.M.L., Frank, M.J., Larcher, K., Fellows, L.K., Clark, C.A., Leyton, M., Dagher, A., 2015. Striatal D1 and D2 signaling differentially predict learning from positive and negative outcomes. Neuroimage 109, 95-101.

Cromwell, H.C., Schultz, W., 2003. Effects of expectations for different reward magnitudes on neuronal activity in primate striatum. J. Neurophysiol. 89, 2823-2838.

Cui, G., Jun, S.B., Jin, X., Pham, M.D., Vogel, S.S., Lovinger, D.M., Costa, R.M., 2013. Concurrent activation of striatal direct and indirect pathways during action initiation. Nature 494, 238-242.

Cunningham, C.L., Howard, M.A., Gill, S.J., Rubinstein, M., Low, M.J., Grandy, D.K., 2000. Ethanol-conditioned place preference is reduced in dopamine D2 receptor-deficient mice. Pharmacol. Biochem. Behav. 67, 693-699.

D'souza, U.M., 2010. Gene and promoter structures of the dopamine receptors. In: Neve, K.A. (Ed.), The Dopamine Receptors, The Receptors. Humana Press, 23-46.

Dautan, D., Huerta-Ocampo, I., Witten, I.B., Deisseroth, K., Bolam, J.P., Gerdjikov, T., Mena-Segovia, J., 2014. A major external source of cholinergic innervation of the striatum and nucleus accumbens originates in the brainstem. J. Neurosci. 34, 4509-4518.

Delgado, M.R., Nystrom, L.E., Fissell, C., Noll, D.C., Fiez, J.A., 2000. Tracking the hemodynamic responses to reward and punishment in the striatum. J. Neurophysiol. 84, 3072-3077.

Delgado, M.R., 2007. Reward-related responses in the human striatum. Ann. N. Y. Acad. Sci. 1104, 70-88.

Deng, Y.-P., Lei, W.-L., Reiner, A., 2006. Differential perikaryal localization in rats of D1 and D2 dopamine receptors on striatal projection neuron types identified by retrograde labeling. J. Chem. Neuroanat. 32, 101-116.

Dickinson, A., Smith, J., Mirenowicz, J., 2000. Dissociation of Pavlovian and instrumental incentive learning under dopamine antagonists. Behav. Neurosci. $114,468-483$.

Donoghue, J.P., Herkenham, M., 1986. Neostriatal projections from individual cortical fields conform to histochemically distinct striatal compartments in the rat. Brain Res. 365, 397-403.

Drago, J., Gerfen, C.R., Lachowicz, J.E., Steiner, H., Hollon, T.R., Love, P.E., Ooi, G.T., Grinberg, A., Lee, E.J., Huang, S.P., 1994. 1994: Altered striatal function in a mutant mouse lacking D1A dopamine receptors. Proc. Natl. Acad. Sci. U. S. A 91, 12564-12568

Drago, J., Gerfen, C.R., Westphal, H., Steiner, H., 1996. D1 dopamine receptor-deficient mouse: cocaine-induced regulation of immediate-early gene and substance P expression in the striatum. Neuroscience 74, 813-823.

Dreher, J.K., Jackson, D.M., 1989. Role of D1 and D2 dopamine receptors in mediating locomotor activity elicited from the nucleus accumbens of rats. Brain Res. 487, 267-277.

Durieux, P.F., Bearzatto, B., Guiducci, S., Buch, T., Waisman, A., Zoli, M., Schiffmann, S.N., de Kerchove d'Exaerde, A., 2009. D2'R striatopallidal neurons inhibit both locomotor and drug reward processes. Nat. Neurosci. 12, 393-395.

Eisenegger, C., Naef, M., Linssen, A., Clark, L., Gandamaneni, P.K., Müller, U., Robbins, T.W., 2014. Role of dopamine D2 receptors in human reinforcement learning. Neuropsychopharmacology 39, 2366-2375.

El-Ghundi, M., George, S.R., Drago, J., Fletcher, P.J., Fan, T., Nguyen, T., Liu, C., Sibley, D.R., Westphal, H., O’Dowd, B.F., 1998. Disruption of dopamine D1 receptor gene expression attenuates alcohol-seeking behavior. Eur. J. Pharmacol. 353, 149-158.

El-Ghundi, M., O’Dowd, B.F., Erclik, M., George, S.R., 2003. Attenuation of sucrose reinforcement in dopamine D1 receptor deficient mice. Eur. J. Neurosci. 17, $851-862$.

Elmer, G.I., Pieper, J.O., Rubinstein, M., Low, M.J., Grandy, D.K., Wise, R.A., 2002. Failure of intravenous morphine to serve as an effective instrumental reinforcer in dopamine D2 receptor knock-out mice. J. Neurosci. 22 (RC224. 20026412).

English, D.F., Ibanez-Sandoval, O., Stark, E., Tecuapetla, F., Buzsáki, G., Deisseroth, K., Tepper, J.M., Koos, T., 2012. GABAergic circuits mediate the reinforcement-related signals of striatal cholinergic interneurons. Nat. Neurosci. 15, 123-130.

Ferguson, S.M., Eskenazi, D., Ishikawa, M., Wanat, M.J., Phillips, P.E.M., Dong, Y. Roth, B.L., Neumaier, J.F., 2011. Transient neuronal inhibition reveals opposing roles of indirect and direct pathways in sensitization. Nat. Neurosci. 14, 22-24.

Fink, H., Morgenstern, R., Ott, T., 1991. CCK-8 modulates D2 receptor agonist-induced hypermotility in the nucleus accumbens. Brain Res. Bull. 26, 437-440.

Ford, C.P., 2014. The role of D2-autoreceptors in regulating dopamine neuron activity and transmission. Neuroscience 282C, 13-22.

Francis, T.C., Chandra, R., Friend, D.M., Finkel, E., Dayrit, G., Miranda, J., Brooks, J.M., Iñiguez, S.D., O’Donnell, P., Kravitz, A., Lobo, M.K., 2015. Nucleus accumbens medium spiny neuron subtypes mediate depression-related outcomes to social defeat stress. Biol. Psychiatry 77, 212-222.

Frank, M.J., Moustafa, A.A., Haughey, H.M., Curran, T., Hutchison, K.E., 2007. Genetic triple dissociation reveals multiple roles for dopamine in reinforcement learning. Proc. Natl. Acad. Sci. 104, 16311-16316.

Frank, M.J., Seeberger, L.C., O'Reilly, R.C., 2004. By carrot or by stick: cognitive reinforcement learning in Parkinsonism. Science 306, 1940-1943.

Frederick, A.L., Yano, H., Trifilieff, P., Vishwasrao, H.D., Biezonski, D., Mészáros, J., Urizar, E., Sibley, D.R., Kellendonk, C., Sonntag, K.C., Graham, D.L., Colbran, R.J., Stanwood, G.D., Javitch, J.A., 2015. Evidence against dopamine D1/D2 receptor heteromers. Mol. Psychiatry 20, 1373-1385. 
Freund, T.F., Powell, J.F., Smith, A.D., 1984. Tyrosine hydroxylase-immunoreactive boutons in synaptic contact with identified striatonigral neurons, with particular reference to dendritic spines. Neuroscience 13, 1189-1215.

Fujiyama, F., Unzai, T., Nakamura, K., Nomura, S., Kaneko, T., 2006. Difference in organization of corticostriatal and thalamostriatal synapses between patch and matrix compartments of rat neostriatum. Eur. J. Neurosci. 24, 2813-2824

Fuxe, K., Marcellino, D., Borroto-Escuela, D.O., Guescini, M., Fernández-Dueñas, V., Tanganelli, S., Rivera, A., Ciruela, F., Agnati, L.F., 2010. Adenosine-dopamine interactions in the pathophysiology and treatment of CNS disorders. CNS Neurosci. Ther. 16, e18-e42.

Gallardo, C.M., Darvas, M., Oviatt, M., Chang, C.H., Michalik, M., Huddy, T.F., Meyer E.E., Shuster, S.A., Aguayo, A., Hill, E.M., Kiani, K., Ikpeazu, J., Martinez, J.S., Purpura, M., Smit, A.N., Patton, D.F., Mistlberger, R.E., Palmiter, R.D., Steele, A.D., 2014. Dopamine receptor 1 neurons in the dorsal striatum regulate food anticipatory circadian activity rhythms in mice. eLife 3, e03781.

Gangarossa, G., Espallergues, J., De Kerchove D’Exaerde, A., El Mestikawy, S., Gerfen, C., Hervé, D., Girault, J.-A., Valjent, E., 2013a. Distribution and compartmental organization of GABAergic medium-sized spiny neurons in the mouse nucleus accumbens. Front. Neural Circuits 7, 22.

Gangarossa, G., Espallergues, J., Mailly, P., De Bundel, D., de Kerchove d'Exaerde, A Hervé, D., Girault, J.-A., Valjent, E., Krieger, P., 2013b. Spatial distribution of D1R- and D2R-expressing medium-sized spiny neurons differs along the rostro-caudal axis of the mouse dorsal striatum. Front. Neural Circuits, 7

Garris, P.A., Ciolkowski, E.L., Pastore, P., Wightman, R.M., 1994. Efflux of dopamine from the synaptic cleft in the nucleus accumbens of the rat brain. J. Neurosci. 14, 6084-6093.

Gerfen, C.R., Young, W.S., 1988. Distribution of striatonigral and striatopallida peptidergic neurons in both patch and matrix compartments: an in situ hybridization histochemistry and fluorescent retrograde tracing study. Brain Res. 460, 161-167.

Gerfen, C.R., Herkenham, M., Thibault, J., 1987. The neostriatal mosaic: II. Patchand matrix-directed mesostriatal dopaminergic and non-dopaminergic systems. J. Neurosci. 7, 3915-3934

Gerfen, C.R., Engber, T.M., Mahan, L.C., Susel, Z., Chase, T.N., Monsma, F.J., Sibley, D.R., 1990. D1 and D2 dopamine receptor-regulated gene expression of striatonigral and striatopallidal neurons. Science 250, 1429-1432.

Gerfen, C.R., 1984. The neostriatal mosaic: compartmentalization of corticostriatal input and striatonigral output systems. Nature 311, 461-464.

Gerfen, C.R., 1985. The neostriatal mosaic. I. Compartmental organization of projections from the striatum to the substantia nigra in the rat. J. Comp. Neurol. 236, 454-476.

Gerfen, C.R., 1992. The neostriatal mosaic: multiple levels of compartmental organization. Trends Neurosci. 15, 133-139.

Gertler, T.S., Chan, C.S., Surmeier, D.J., 2008. Dichotomous anatomical properties of adult striatal medium spiny neurons. J. Neurosci. 28, 10814-10824.

Ghitza, U.E., Fabbricatore, A.T., Prokopenko, V., Pawlak, A.P., West, M.O., 2003. Persistent cue-evoked activity of accumbens neurons after prolonged abstinence from self-administered cocaine. J. Neurosci. 23, 7239-7245.

Giménez-Amaya, J.M., McFarland, N.R., de las Heras, S., Haber, S.N., 1995. Organization of thalamic projections to the ventral striatum in the primate. J. Comp. Neurol. 354, 127-149.

Gittis, A.H., Kreitzer, A.C., 2012. Striatal microcircuitry and movement disorders. Trends Neurosci. 35, 557-564.

Gittis, A.H., Nelson, A.B., Thwin, M.T., Palop, J.J., Kreitzer, A.C., 2010. Distinct roles of GABAergic interneurons in the regulation of striatal output pathways. J. Neurosci. 30, 2223-2234.

Gong, S., Doughty, M., Harbaugh, C.R., Cummins, A., Hatten, M.E., Heintz, N., Gerfen, C.R., 2007. Targeting cre recombinase to specific neuron populations with bacterial artificial chromosome constructs. J. Neurosci. 27, 9817-9823.

Grace, A.A., Bunney, B.S., 1984. The control of firing pattern in nigral dopamine neurons: burst firing. J. Neurosci. 4, 2877-2890.

Grace, A.A., Floresco, S.B., Goto, Y., Lodge, D.J., 2007. Regulation of firing of dopaminergic neurons and control of goal-directed behaviors. Trends Neurosci. 30, 220-227.

Grace, A.A., 1991. Phasic versus tonic dopamine release and the modulation of dopamine system responsivity: a hypothesis for the etiology of schizophrenia. Neuroscience 41, 1-24

Grace, A.A., 2000. Gating of information flow within the limbic system and the pathophysiology of schizophrenia. Brain Res. Brain Res. Rev. 31, 330-341.

Granado, N., Ortiz, O., Suárez, L.M., Martín, E.D., Ceña, V., Solís, J.M., Moratalla, R., 2008. D1 but not D5 dopamine receptors are critical for LTP, spatial learning and LTP-Induced arc and zif268 expression in the hippocampus. Cereb. Cortex N. Y. N 18, 1-12

Graveland, G.A., DiFiglia, M., 1985. The frequency and distribution of medium-sized neurons with indented nuclei in the primate and rodent neostriatum. Brain Res. 327, 307-311

Graveland, G.A., Williams, R.S., DiFiglia, M., 1985. A Golgi study of the human neostriatum: neurons and afferent fibers. J. Comp. Neurol. 234, 317-333.

Graybiel, A.M., Ragsdale, C.W., 1978. Histochemically distinct compartments in the striatum of human monkeys, and cat demonstrated by acetylthiocholinesterase staining. Proc. Natl. Acad. Sci. U. S. A. 75, 5723-5726.

Graybiel, A.M., Rauch, S.L., 2000. Toward a neurobiology of obsessive-compulsive disorder. Neuron 28, 343-347.

Graybiel, A.M., Baughman, R.W., Eckenstein, F., 1986. Cholinergic neuropil of the striatum observes striosomal boundaries. Nature 323, 625-627.
Graybiel, A.M., 1995. Building action repertoires: memory and learning functions of the basal ganglia. Curr. Opin. Neurobiol. 5, 733-741.

Greif, G.J., Lin, Y.J., Liu, J.C., Freedman, J.E., 1995. Dopamine-modulated potassium channels on rat striatal neurons: specific activation and cellular expression. J. Neurosci. 15, 4533-4544.

Gremel, C.M., Costa, R.M., 2013. Orbitofrontal and striatal circuits dynamically encode the shift between goal-directed and habitual actions. Nat. Commun. 4, 2264.

Groenewegen, H.J., 2003. The basal ganglia and motor control. Neural Plast. 10, 107-120.

Guo, Q., Wang, D., He, X., Feng, Q., Lin, R., Xu, F., Fu, L., Luo, M., 2015. Whole-brain mapping of inputs to projection neurons and cholinergic interneurons in the dorsal striatum. PLoS One 10, e0123381.

Håkansson, K., Galdi, S., Hendrick, J., Snyder, G., Greengard, P., Fisone, G., 2006. Regulation of phosphorylation of the GluR1 AMPA receptor by dopamine D2 receptors. J. Neurochem. 96, 482-488.

Haber, S.N., 2003. The primate basal ganglia: parallel and integrative networks. J. Chem. Neuroanat. 26, 317-330.

Haber, S.N., 2011. Neuroanatomy of reward: a view from the ventral striatum. In: Gottfried, J.A. (Ed.), Neurobiology of Sensation and Reward, Frontiers in Neuroscience. CRC Press/Taylor \& Francis, Boca Raton (FL).

Hallett, P.J., Spoelgen, R., Hyman, B.T., Standaert, D.G., Dunah, A.W., 2006 Dopamine D1 activation potentiates striatal NMDA receptors by tyrosine phosphorylation-dependent subunit trafficking. J. Neurosci. 26, 4690-4700.

Hasbi, A., O'Dowd, B.F., George, S.R., 2011. Dopamine D1-D2 receptor heteromer signaling pathway in the brain: emerging physiological relevance. Mol. Brain 4, 26.

Hassani, O.K., Cromwell, H.C., Schultz, W., 2001. Influence of expectation of different rewards on behavior-related neuronal activity in the striatum. J. Neurophysiol. 85, 2477-2489.

Heiman, M., Schaefer, A., Gong, S., Peterson, J.D., Day, M., Ramsey, K.E., Suárez-Fariñas, M., Schwarz, C., Stephan, D.A., Surmeier, D.J., Greengard, P. Heintz, N., 2008. A translational profiling approach for the molecular characterization of CNS cell types. Cell 135, 738-748.

Heller, A.S., Johnstone, T., Shackman, A.J., Light, S.N., Peterson, M.J., Kolden, G.G., Kalin, N.H., Davidson, R.J., 2009. Reduced capacity to sustain positive emotion in major depression reflects diminished maintenance of fronto-striatal brain activation. Proc. Natl. Acad. Sci. 106, 22445-22450.

Herkenham, M., Pert, C.B., 1981. Mosaic distribution of opiate receptors, parafascicular projections and acetylcholinesterase in rat striatum. Nature 291, 415-418.

Hernandez-Lopez, S., Tkatch, T., Perez-Garci, E., Galarraga, E., Bargas, J., Hamm, H., Surmeier, D.J., 2000. D2 dopamine receptors in striatal medium spiny neurons reduce L-type Ca2+ currents and excitability via a novel PLC[beta]1-IP3-calcineurin-signaling cascade. J. Neurosci. 20, 8987-8995.

Hervé, D., Rogard, M., Lévi-Strauss, M., 1995. Molecular analysis of the multiple Golf alpha subunit mRNAs in the rat brain. Brain Res. Mol. Brain Res. 32, 125-134.

Hikida, T., Kaneko, S., Isobe, T., Kitabatake, Y., Watanabe, D., Pastan, I., Nakanishi, S., 2001. Increased sensitivity to cocaine by cholinergic cell ablation in nucleus accumbens. Proc. Natl. Acad. Sci. 98, 13351-13354.

Hikida, T., Kimura, K., Wada, N., Funabiki, K., Nakanishi, S., 2010. Distinct roles of synaptic transmission in direct and indirect striatal pathways to reward and aversive behavior. Neuron 66, 896-907.

Hikida, T., Yawata, S., Yamaguchi, T., Danjo, T., Sasaoka, T., Wang, Y., Nakanishi, S., 2013. Pathway-specific modulation of nucleus accumbens in reward and aversive behavior via selective transmitter receptors. Proc. Natl. Acad. Sci. U. S. A. $110,342-347$

Hikosaka, O., Sakamoto, M., Usui, S., 1989. Functional properties of monkey caudate neurons. III. Activities related to expectation of target and reward. J. Neurophysiol. 61, 814-832.

Hiroi, N., White, N.M., 1991. The amphetamine conditioned place preference: differential involvement of dopamine receptor subtypes and two dopaminergic terminal areas. Brain Res. 552, 141-152.

Hollerman, J.R., Tremblay, L., Schultz, W., 1998. Influence of reward expectation on behavior-related neuronal activity in primate striatum. J. Neurophysiol. 80 947-963.

Ibáñez-Sandoval, O., Tecuapetla, F., Unal, B., Shah, F., Koós, T., Tepper, J.M., 2010. Electrophysiological and morphological characteristics and synaptic connectivity of tyrosine hydroxylase-expressing neurons in adult mouse striatum. J. Neurosci. 30, 6999-7016.

Ibáñez-Sandoval, O., Tecuapetla, F., Unal, B., Shah, F., Koós, T., Tepper, J.M., 2011. A novel functionally distinct subtype of striatal neuropeptide Y interneuron. J. Neurosci. Off. J. Soc. Neurosci. 31, 16757-16769.

Ibáñez-Sandoval, O., Xenias, H.S., Tepper, J.M., Koós, T., 2015. Dopaminergic and cholinergic modulation of striatal tyrosine hydroxylase interneurons. Neuropharmacology 95, 468-476

Ikemoto, S., Glazier, B.S., Murphy, J.M., McBride, W.J., 1997. Role of dopamine D1 and D2 receptors in the nucleus accumbens in mediating reward. J. Neurosci. $17,8580-8587$

Janak, P.H., Chang, J.-Y., Woodward, D.J., 1999. Neuronal spike activity in the nucleus accumbens of behaving rats during ethanol self-administration. Brain Res. 817, 172-184.

Jocham, G., Klein, T.A., Neumann, J., Cramon, D.Y., von Reuter, M., Ullsperger, M., 2009. Dopamine DRD2 polymorphism alters reversal learning and associated neural activity. J. Neurosci. 29, 3695-3704. 
Juckel, G., Schlagenhauf, F., Koslowski, M., Filonov, D., Wüstenberg, T., Villringer, A., Knutson, B., Kienast, T., Gallinat, J., Wrase, J., Heinz, A., 2006. Dysfunction of ventral striatal reward prediction in schizophrenic patients treated with typical, not atypical, neuroleptics. Psychopharmacology (Berl.) 187, 222-228.

Kaneko, S., Hikida, T., Watanabe, D., Ichinose, H., Nagatsu, T., Kreitman, R.J., Pastan, I., Nakanishi, S., 2000. Synaptic integration mediated by striatal cholinergic interneurons in basal ganglia function. Science 289, 633-637.

Kawagoe, R., Takikawa, Y., Hikosaka, O., 1998. Expectation of reward modulates cognitive signals in the basal ganglia. Nat. Neurosci. 1, 411-416.

Kawaguchi, Y., 1997. Neostriatal cell subtypes and their functional roles. Neurosci. Res. 27, 1-8.

Keefe, K.A., Zigmond, M.J., Abercrombie, E.D., 1993. In vivo regulation of extracellular dopamine in the neostriatum: influence of impulse activity and local excitatory amino acids. J. Neural Transm. Gen. Sect. JNT 91, 223-240.

Kimchi, E.Y., Torregrossa, M.M., Taylor, J.R., Laubach, M., 2009. Neuronal correlates of instrumental learning in the dorsal striatum. J. Neurophysiol. 102, 475-489.

Kincaid, A.E., Wilson, C.J., 1996. Corticostriatal innervation of the patch and matrix in the rat neostriatum. J. Comp. Neurol. 374, 578-592.

Klein, T.A., Neumann, J., Reuter, M., Hennig, J., Cramon, D.Y., von Ullsperger, M., 2007. Genetically determined differences in learning from errors. Science 318, $1642-1645$.

Knutson, B., Adams, C.M., Fong, G.W., Hommer, D., 2001. Anticipation of increasing monetary reward selectively recruits nucleus accumbens. J. Neurosci. 21, RC159.

Kobayashi, M., Iaccarino, C., Saiardi, A., Heidt, V., Bozzi, Y., Picetti, R., Vitale, C., Westphal, H., Drago, J., Borrelli, E., 2004. Simultaneous absence of dopamine D1 and D2 receptor-mediated signaling is lethal in mice. Proc. Natl. Acad. Sci. U. S. A. 101, 11465-11470.

Koob, G.F., Volkow, N.D., 2010. Neurocircuitry of addiction. Neuropsychopharmacology 35, 217-238.

Kornhuber, J., Kornhuber, M.E., 1986. Presynaptic dopaminergic modulation of cortical input to the striatum. Life Sci. 39, 674-699.

Krack, P., Hariz, M.I., Baunez, C., Guridi, J., Obeso, J.A., 2010. Deep brain stimulation: from neurology to psychiatry? Trends Neurosci. 33, 474-484.

Kravitz, A.V., Kreitzer, A.C., 2012. Striatal mechanisms underlying movement reinforcement, and punishment. Physiol. Bethesda Md 27.

Kravitz, A.V., Freeze, B.S., Parker, P.R.L., Kay, K., Thwin, M.T., Deisseroth, K., Kreitzer, A.C., 2010. Regulation of parkinsonian motor behaviours by optogenetic control of basal ganglia circuitry. Nature 466, 622-626.

Kravitz, A.V., Tye, L.D., Kreitzer, A.C., 2012. Distinct roles for direct and indirect pathway striatal neurons in reinforcement. Nat. Neurosci. 15, 816-818.

Kreitzer, A.C., Malenka, R.C., 2008. Striatal plasticity and basal ganglia circuit function. Neuron 60, 543-554

Kreitzer, A.C., 2009. Physiology and pharmacology of striatal neurons. Annu. Rev. Neurosci. 32, 127-147.

Kupchik, Y.M., Brown, R.M., Heinsbroek, J.A., Lobo, M.K., Schwartz, D.J., Kalivas, P.W., 2015. Coding the direct/indirect pathways by D1 and D2 receptors is not valid for accumbens projections. Nat. Neurosci. (advance online publication).

Lanciego, J.L., Gonzalo, N., Castle, M., Sanchez-Escobar, C., Aymerich, M.S., Obeso, J.A., 2004. Thalamic innervation of striatal and subthalamic neurons projecting to the rat entopeduncular nucleus. Eur. J. Neurosci. 19, 1267-1277.

Lapper, S.R., Smith, Y., Sadikot, A.F., Parent, A., Bolam, J.P., 1992. Cortical input to parvalbumin-immunoreactive neurones in the putamen of the squirrel monkey. Brain Res. 580, 215-224.

Lee, S.P., So, C.H., Rashid, A.J., Varghese, G., Cheng, R., Lança, AJ, O’Dowd, B.F., George, S.R., 2004. Dopamine D1 and D2 receptor Co-activation generates a novel phospholipase C-mediated calcium signal. J. Biol. Chem. 279, 35671-35678.

Lester, J., Fink, S., Aronin, N., DiFiglia, M., 1993. Colocalization of D1 and D2 dopamine receptor mRNAs in striatal neurons. Brain Res. 621, 106-110.

Lex, A., Hauber, W., 2008. Dopamine D1 and D2 receptors in the nucleus accumbens core and shell mediate Pavlovian-instrumental transfer. Learn. Mem. 15, 483-491.

Liao, R.-M., 2008. Development of conditioned place preference induced by intra-accumbens infusion of amphetamine is attenuated by co-infusion of dopamine D1 and D2 receptor antagonists. Pharmacol. Biochem. Behav. 89 367-373.

Liu, F., Wan, Q., Pristupa, Z.B., Yu, X.-M., Wang, Y.T., Niznik, H.B., 2000. Direct protein-protein coupling enables cross-talk between dopamine D5 and -aminobutyric acid A receptors. Nature 403, 274-280.

Liu, X., Hairston, J., Schrier, M., Fan, J., 2011. Common and distinct networks underlying reward valence and processing stages: a meta-analysis of functional neuroimaging studies. Neurosci. Biobehav. Rev. 35, 1219-1236.

Lobo, M.K., Nestler, E.J., 2011. The striatal balancing act in drug addiction: distinct roles of direct and indirect pathway medium spiny neurons. Front. Neuroanat. 5 .

Lobo, M.K., Karsten, S.L., Gray, M., Geschwind, D.H., Yang, X.W., 2006. FACS-array profiling of striatal projection neuron subtypes in juvenile and adult mouse brains. Nat. Neurosci. 9, 443-452.

Lobo, M.K., Cui, Y., Ostlund, S.B., Balleine, B.W., Yang, X.W., 2007. Genetic control of instrumental conditioning by striatopallidal neuron-specific S1 P receptor Gpr6. Nat. Neurosci. 10, 1395-1397.

Lobo, M.K., Covington, H.E., Chaudhury, D., Friedman, A.K., Sun, H., Damez-Werno, D., Dietz, D.M., Zaman, S., Koo, J.W., Kennedy, P.J., Mouzon, E., Mogri, M., Neve, R.L., Deisseroth, K., Han, M.-H., Nestler, E.J., 2010. Cell Type-Specific loss of
BDNF signaling mimics optogenetic control of cocaine reward. Science 330, 385-390.

Lu, X.Y., Ghasemzadeh, M.B., Kalivas, P.W., 1998. Expression of D1 receptor, D2 receptor, substance $\mathrm{P}$ and enkephalin messenger RNAs in the neurons projecting from the nucleus accumbens. Neuroscience 82, 767-780.

Luo, Z., Volkow, N.D., Heintz, N., Pan, Y., Du, C., 2011. Acute cocaine induces fast activation of D1 receptor and progressive deactivation of D2 receptor striatal neurons: in vivo optical microprobe [Ca2+]i imaging. J. Neurosci. 31, 13180-13190.

Maldonado, R., Saiardi, A., Valverde, O., Samad, T.A., Roques, B.P., Borrelli, E., 1997. Absence of opiate rewarding effects in mice lacking dopamine D2 receptors. Nature 388, 586-589.

Managò, F., Castellano, C., Oliverio, A., Mele, A., Leonibus, E.D., 2009. Role of dopamine receptors subtypes D1-like and D2-like, within the nucleus accumbens subregions, core and shell, on memory consolidation in the one-trial inhibitory avoidance task. Learn. Mem. 16, 46-52.

Marcott, P.F., Mamaligas, A.A., Ford, C.P., 2014. Phasic dopamine release drives rapid activation of striatal D2-Receptors. Neuron 84, 164-176.

Maura, G., Giardi, A., Raiteri, M., 1988. Release-regulating D-2 dopamine receptors are located on striatal glutamatergic nerve terminals. J. Pharmacol. Exp. Ther. 247, 680-684.

Maurice, N., Mercer, J., Chan, C.S., Hernandez-Lopez, S., Held, J., Tkatch, T., Surmeier, D.J., 2004. D2 dopamine receptor-mediated modulation of voltage-dependent $\mathrm{Na}+$ channels reduces autonomous activity in striatal cholinergic interneurons. J. Neurosci. 24, 10289-10301.

McFarland, N.R., Haber, S.N., 2000. Convergent inputs from thalamic motor nuclei and frontal cortical areas to the dorsal striatum in the primate. J. Neurosci. 20, 3798-3813.

Miyachi, S., Hikosaka, O., Lu, X., 2002. Differential activation of monkey striatal neurons in the early and late stages of procedural learning. Exp. Brain Res. 146 $122-126$.

Moore, H., West, A.R., Grace, A.A., 1999. The regulation of forebrain dopamine transmission: relevance to the pathophysiology and psychopathology of schizophrenia. Biol. Psychiatry 46, 40-55.

Morris, G., Arkadir, D., Nevet, A., Vaadia, E., Bergman, H., 2004. Coincident but distinct messages of midbrain dopamine and striatal tonically active neurons. Neuron 43, 133-143.

Nair, V.D., Sealfon, S.C., 2003. Agonist-specific transactivation of phosphoinositide 3-kinase signaling pathway mediated by the dopamine D2 receptor. J. Biol. Chem. 278, 47053-47061.

Nakamura, K., Hikosaka, O., 2006. Role of dopamine in the primate caudate nucleus in reward modulation of saccades. J. Neurosci. 26, 5360-5369.

Nakamura, T., Sato, A., Kitsukawa, T., Momiyama, T., Yamamori, T., Sasaoka, T., 2014. Distinct motor impairments of dopamine D1 and D2 receptor knockout mice revealed by three types of motor behavior. Front. Integr. Neurosci. 8, 56.

Nauta, W.J.H., Smith, G.P., Faull, R.L.M., Domesick, V.B., 1978. Efferent connections and nigral afferents of the nucleus accumbens septi in the rat. Neuroscience 3, 385-401.

Nicola, S.M., Yun, I.A., Wakabayashi, K.T., Fields, H.L., 2004. Firing of nucleus accumbens neurons during the consummatory phase of a discriminative stimulus task depends on previous reward predictive cues. J. Neurophysiol. 91 1866-1882.

Nicola, S.M., 2007. The nucleus accumbens as part of a basal ganglia action selection circuit. Psychopharmacology (Berl.) 191, 521-550.

Nishino, H., Ono, T., Sasaki, K., Fukuda, M., Muramoto, K., 1984. Caudate unit activity during operant feeding behavior in monkeys and modulation by cooling prefrontal cortex. Behav. Brain Res. 11, 21-33.

Niv, Y., Daw, N.D., Joel, D., Dayan, P., 2006. Tonic dopamine: opportunity costs and the control of response vigor. Psychopharmacology (Berl.) 191, 507-520.

Nowend, K.L., Arizzi, M., Carlson, B.B., Salamone, J.D., 2001. D1 or D2 antagonism in nucleus accumbens core or dorsomedial shell suppresses lever pressing for food but leads to compensatory increases in chow consumption. Pharmacol. Biochem. Behav. 69, 373-382.

Nunes, E.J., Randall, P.A., Santerre, J.L., Given, A.B., Sager, T.N., Correa, M., Salamone, J.D., 2010. Differential effects of selective adenosine antagonists on the effort-related impairments induced by dopamine D1 and D2 antagonism. Neuroscience 170, 268-280.

O’Doherty, J.P., Deichmann, R., Critchley, H.D., Dolan, R.J., 2002. Neural responses during anticipation of a primary taste reward. Neuron 33, 815-826.

Olson, L., Seiger, A., Fuxe, K., 1972. Heterogeneity of striatal and limbic dopamine innervation: highly fluorescent islands in developing and adult rats. Brain Res. $44,283-288$.

Olson, P.A., Tkatch, T., Hernandez-Lopez, S., Ulrich, S., Ilijic, E., Mugnaini, E., Zhang, H., Bezprozvanny, I., Surmeier, D.J., 2005. G-protein-coupled receptor modulation of striatal CaV1.3L-type Ca2+ channels is dependent on a Shank-binding domain. J. Neurosci. 25, 1050-1062.

Parent, A., Hazrati, L.-N., 1995. Functional anatomy of the basal ganglia I. The cortico-basal ganglia-thalamo-cortical loop. Brain Res. Rev. 20, 91-127.

Parker, J.G., Zweifel, L.S., Clark, J.J., Evans, S.B., Phillips, P.E.M., Palmiter, R.D., 2010. Absence of NMDA receptors in dopamine neurons attenuates dopamine release but not conditioned approach during Pavlovian conditioning. Proc. Natl. Acad. Sci. U. S. A. 107, 13491-13496.

Parsons, L.H., Justice, J.B., 1992. Extracellular concentration and in vivo recovery of dopamine in the nucleus accumbens using microdialysis. J. Neurochem. 58, 212-218. 
Peoples, L.L., West, M.O., 1996. Phasic firing of single neurons in the rat nucleus accumbens correlated with the timing of intravenous cocaine self-Administration. J. Neurosci. 16, 3459-3473.

Perreault, M.L., Hasbi, A., Alijaniaram, M., Fan, T., Varghese, G., Fletcher, P.J., Seeman, P., O’Dowd, B.F., George, S.R., 2010. The dopamine D1-D2 receptor heteromer localizes in dynorphin/enkephalin neurons: increased high affinity state following amphetamine and in schizophrenia. J. Biol. Chem. 285, 36625-36634

Perreault, M.L., Hasbi, A., O’Dowd, B.F., George, S.R., 2011. The dopamine D1-D2 receptor heteromer in striatal medium spiny neurons: evidence for a third distinct neuronal pathway in basal ganglia. Front. Neuroanat. 5.

Perreault, M.L., Hasbi, A., O’Dowd, B.F., George, S.R., 2014. Heteromeric dopamine receptor signaling complexes: emerging neurobiology and disease relevance. Neuropsychopharmacology 39, 156-168.

Perreault, M.L., Fan, T., Alijaniaram, M., O’Dowd, B.F., George, S.R., 2012. Dopamine D1-D2 receptor heteromer in dual phenotype GABA/glutamate-coexpressing striatal medium spiny neurons: regulation of BDNF, GAD67 and VGLUT1/2. PloS One 7, e33348

Picetti, R., Saiardi, A., Abdel Samad, T., Bozzi, Y., Baik, J.H., Borrelli, E., 1997. Dopamine D2 receptors in signal transduction and behavior. Crit. Rev. Neurobiol. 11, 121-142.

Pina, M.M., Cunningham, C.L., 2014. Effects of dopamine receptor antagonists on the acquisition of ethanol-induced conditioned place preference in mice. Psychopharmacology (Berl.) 231, 459-468.

Pisani, A., Bonsi, P., Centonze, D., Calabresi, P., Bernardi, G., 2000. Activation of D2-like dopamine receptors reduces synaptic inputs to striatal cholinergic interneurons. J. Neurosci. 20, RC69.

Planert, H., Szydlowski, S.N., Hjorth, J.J.J., Grillner, S., Silberberg, G., 2010. Dynamics of synaptic transmission between fast-spiking interneurons and striatal projection neurons of the direct and indirect pathways. J. Neurosci. 30 3499-3507.

Ragsdale, C.W., Graybiel, A.M. 1988. Fibers from the basolateral nucleus of the amygdala selectively innervate striosomes in the caudate nucleus of the cat. J Comp. Neurol. 269, 506-522.

Redgrave, P., Gurney, K., 2006. The short-latency dopamine signal: a role in discovering novel actions? Nat. Rev. Neurosci. 7, 967-975.

Richfield, E.K., Penney, J.B., Young, A.B., 1989. Anatomical and affinity state comparisons between dopamine D1 and D2 receptors in the rat central nervous system. Neuroscience 30, 767-777.

Risinger, F.O., Freeman, P.A., Rubinstein, M., Low, M.J., Grandy, D.K., 2000. Lack of operant ethanol self-administration in dopamine D2 receptor knockout mice. Psychopharmacology (Berl.) 152, 343-350.

Roitman, M.F., Wheeler, R.A., Carelli, R.M., 2005. Nucleus accumbens neurons are innately tuned for rewarding and aversive taste stimuli encode thei predictors, and are linked to motor output. Neuron 45, 587-597.

Rolls, E.T., 1994. Neurophysiology and cognitive functions of the striatum. Rev. Neurol. (Paris) 150, 648-660.

Russo, S.J., Nestler, E.J., 2013. The brain reward circuitry in mood disorders. Nat. Rev. Neurosci. 14, 609-625.

Sadikot, A.F., Parent, A., Smith, Y., Bolam, J.P., 1992. Efferent connections of the centromedian and parafascicular thalamic nuclei in the squirrel monkey: a light and electron microscopic study of the thalamostriatal projection in relation to striatal heterogeneity. J. Comp. Neurol. 320, 228-242.

Samejima, K., Ueda, Y., Doya, K., Kimura, M., 2005. Representation o action-specific reward values in the striatum. Science 310, 1337-1340.

Saunders, A., Oldenburg, I.A., Berezovskii, V.K., Johnson, C.A., Kingery, N.D., Elliott H.L., Xie, T., Gerfen, C.R., Sabatini, B.L., 2015. A direct GABAergic output from the basal ganglia to frontal cortex. Nature 521, 85-89.

Scheuer, T., Catterall, W.A., 2006. Control of neuronal excitability by phosphorylation and dephosphorylation of sodium channels. Biochem. Soc. Trans. 34, 1299-1302.

Schmitzer-Torbert, N., Redish, A.D., 2004. Neuronal activity in the rodent dorsal striatum in sequential navigation: separation of spatial and reward responses on the multiple t task. J. Neurophysiol. 91, 2259-2272.

Schultz, W., Romo, R., 1988. Neuronal activity in the monkey striatum during the initiation of movements. Exp. Brain Res. 71, 431-436.

Schultz, W., Apicella, P., Scarnati, E., Ljungberg, T., 1992. Neuronal activity in monkey ventral striatum related to the expectation of reward. J. Neurosci. 12, 4595-4610.

Schultz, W., Dayan, P., Montague, P.R., 1997. A neural substrate of prediction and reward. Science 275, 1593-1599.

Schultz, W., 1997. Dopamine neurons and their role in reward mechanisms. Curr. Opin. Neurobiol. 7, 191-197.

Schultz, W., 2002. Getting formal with dopamine and reward. Neuron 36, 241-263.

Self, D.W., 2010. Dopamine Receptor Subtypes in Reward and Relapse. In: Neve, K.A. (Ed.), The Dopamine Receptors, The Receptors. Humana Press, 479-524

Sesack, S.R., Grace, A.A., 2010. Cortico-Basal ganglia reward network: microcircuitry. Neuropsychopharmacology 35, 27-47.

Seymour, B., Daw, N., Dayan, P., Singer, T., Dolan, R., 2007. Differential encoding of losses and gains in the human striatum. J. Neurosci. 27, 4826-4831.

Shidara, M., Aigner, T.G., Richmond, B.J., 1998. Neuronal signals in the monkey ventral striatum related to progress through a predictable series of trials. J Neurosci. 18, 2613-2625

Sidibé, M., Smith, Y., 1999. Thalamic inputs to striatal interneurons in monkeys: synaptic organization and co-localization of calcium binding proteins. Neuroscience 89, 1189-1208.
Smith, A.D., Bolam, J.P., 1990. The neural network of the basal ganglia as revealed by the study of synaptic connections of identified neurones. Trends Neurosci. 13, 259-265.

Smith, D.R., Striplin, C.D., Geller, A.M., Mailman, R.B., Drago, J., Lawler, C.P., Gallagher, M., 1998. Behavioural assessment of mice lacking D1A dopamine receptors. Neuroscience $86,135-146$.

Smith, J.W., Fetsko, L.A., Xu, R., Wang, Y., 2002. Dopamine D2L receptor knockout mice display deficits in positive and negative reinforcing properties of morphine and in avoidance learning. Neuroscience 113, 755-765.

Smith, Y., Raju, D.V., Pare, J.-F., Sidibe, M., 2004. The thalamostriatal system: a highly specific network of the basal ganglia circuitry. Trends Neurosci. 27, 520-527.

Smith, Y., Raju, D., Nanda, B., Pare, J.-F., Galvan, A., Wichmann, T., 2009. The thalamostriatal systems: anatomical and functional organization in normal and parkinsonian states. Brain Res. Bull. 78, 60-68.

Smith, R.J., Lobo, M.K., Spencer, S., Kalivas, P.W., 2013. Cocaine-induced adaptations in D1 and D2 accumbens projection neurons (a dichotomy not necessarily synonymous with direct and indirect pathways). Curr. Opin. Neurobiol. 23, 546-552.

Snyder, G.L., Allen, P.B., Fienberg, A.A., Valle, C.G., Huganir, R.L., Nairn, A.C., Greengard, P., 2000. Regulation of phosphorylation of the GluR1 AMPA receptor in the neostriatum by dopamine and psychostimulants In vivo. J Neurosci. 20, 4480-4488.

Soares-Cunha, C., Coimbra, B., Borges, S., Carvalho, M.M., Rodrigues, A.J., Sousa, N., 2014. The motivational drive to natural rewards is modulated by prenatal glucocorticoid exposure. Transl. Psychiatry 4, e397.

Soares-Cunha, C., Coimbra, B., David-Pereira, A., Borges, S., Pinto, L., Sousa, N. Rodrigues, A.J., 2016. Activation of D2 dopamine receptor-expressing neurons in the nucleus accumbens increases motivation. Nat. Commun. (Accepted for publication)

Song, S.S., Kang, B.J., Wen, L., Lee, H.J., Sim, H.-R., Kim, T.H., Yoon, S., Yoon, B.-J., Augustine, G.J., Baik, J.-H., 2014. Optogenetics reveals a role for accumbal medium spiny neurons expressing dopamine D2 receptors in cocaine-induced behavioral sensitization. Front. Behav. Neurosci. 8, 336.

Steinberg, E.E., Boivin, J.R., Saunders, B.T., Witten, I.B., Deisseroth, K., Janak, P.H. 2014. Positive reinforcement mediated by midbrain dopamine neurons requires D1 and D2 receptor activation in the nucleus accumbens. PLoS One 9, e94771.

Stoof, J.C., Kebabian, J.W., 1984. Two dopamine receptors: biochemistry physiology and pharmacology. Life Sci. 35, 2281-2296.

Stuber, G.D., Stamatakis, A.M., Kantak, P.A., 2015. Considerations when using cre-Driver rodent lines for studying ventral tegmental area circuitry. Neuron 85, 439-445.

Surmeier, D.J., Eberwine, J., Wilson, C.J., Cao, Y., Stefani, A., Kitai, S.T., 1992. Dopamine receptor subtypes colocalize in rat striatonigral neurons. Proc. Natl. Acad. Sci. U. S. A. 89, 10178-10182.

Surmeier, D.J., Bargas, J., Hemmings, H.C., Nairn, A.C., Greengard, P., 1995 Modulation of calcium currents by a D1 dopaminergic protein kinase/phosphatase cascade in rat neostriatal neurons. Neuron 14, 385-397.

Surmeier, D.J., Ding, J., Day, M., Wang, Z., Shen, W., 2007. D1 and D2 dopamine-receptor modulation of striatal glutamatergic signaling in striatal medium spiny neurons. Trends Neurosci. 30, 228-235.

Surmeier, D.J., Carrillo-Reid, L., Bargas, J., 2011. Dopaminergic modulation of striatal neurons, circuits, and assemblies. Neuroscience 198, 3-18.

Svenningsson, P., Nishi, A., Fisone, G., Girault, J.-A., Nairn, A.C., Greengard, P., 2004. DARPP-32: an integrator of neurotransmission. Annu. Rev. Pharmacol. Toxicol. 44, 269-296.

Tai, L.-H., Lee, A.M., Benavidez, N., Bonci, A., Wilbrecht, L., 2012. Transien stimulation of distinct subpopulations of striatal neurons mimics changes in action value. Nat. Neurosci. 15, 1281-1289.

Takakusaki, K., Saitoh, K., Harada, H., Kashiwayanagi, M., 2004. Role of basa ganglia-brainstem pathways in the control of motor behaviors. Neurosci. Res. 50, 137-151.

Tang, C., Pawlak, A.P., Prokopenko, V., West, M.O., 2007. Changes in activity of the striatum during formation of a motor habit. Eur. J. Neurosci. 25, 1212-1227.

Tepper, J.M., Bolam, J.P., 2004. Functional diversity and specificity of neostriatal interneurons. Curr. Opin. Neurobiol. 14, 685-692.

Tepper, J.M., Wilson, C.J., Koós, T., 2008. Feedforward and feedback inhibition in neostriatal GABAergic spiny neurons. Brain Res. Rev. 58, 272-281.

Tepper, J.M., Tecuapetla, F., Koós, T., Ibáñez-Sandoval, O., 2010. Heterogeneity and diversity of striatal GABAergic interneurons. Front. Neuroanat. 4, 150.

Threlfell, S., Lalic, T., Platt, N.J., Jennings, K.A., Deisseroth, K., Cragg, S.J., 2012. Striatal dopamine release is triggered by synchronized activity in cholinergic interneurons. Neuron 75, 58-64.

Tomer, R., Goldstein, R.Z., Wang, G.-J., Wong, C., Volkow, N.D., 2008. Incentive motivation is associated with striatal dopamine asymmetry. Biol. Psychol. 77 98-101.

Tomer, R., Slagter, H.A., Christian, B.T., Fox, A.S., King, C.R., Murali, D., Gluck, M.A., Davidson, R.J., 2013. Love to win or hate to lose? asymmetry of dopamine D2 receptor binding predicts sensitivity to reward versus punishment. J. Cogn. Neurosci. 26, 1039-1048.

Tozzi, A., de Iure, A., Di Filippo, M., Tantucci, M., Costa, C., Borsini, F., Ghiglieri, V., Giampà, C., Fusco, F.R., Picconi, B., Calabresi, P., 2011. The distinct role of medium spiny neurons and cholinergic interneurons in the $D_{2} / A_{2} A$ receptor interaction in the striatum: implications for Parkinson's disease. J. Neurosci. $31,1850-1862$ 
Trifilieff, P., Feng, B., Urizar, E., Winiger, V., Ward, R.D., Taylor, K.M., Martinez, D.M., Moore, H., Balsam, P.D., Simpson, E.H., Javitch, J.A., 2013. Increasing dopamine D2 receptor expression in the adult nucleus accumbens enhances motivation. Mol. Psychiatry 18, 1025-1033.

Tritsch, N.X., Sabatini, B.L., 2012. Dopaminergic modulation of synaptic transmission in cortex and striatum. Neuron 76, 33-50.

Usiello, A., Baik, J.-H., Rougé-Pont, F., Picetti, R., Dierich, A., LeMeur, M., Piazza, P.V., Borrelli, E., 2000. Distinct functions of the two isoforms of dopamine D2 receptors. Nature 408, 199-203.

Vicente, A.M., Galvão-Ferreira, P., Tecuapetla, F., Costa, R.M., 2016. Direct and indirect dorsolateral striatum pathways reinforce different action strategies. Curr. Biol. CB 26, R267-269.

Vilchis, C., Bargas, J., Ayala, G.X., Galván, E., Galarraga, E., 2000. Ca2+ channels that activate $\mathrm{Ca} 2+$-dependent $\mathrm{K}+$ currents in neostriatal neurons. Neuroscience 95 , $745-752$.

Volkow, N.D., Wang, G.J., Fowler, J.S., Hitzemann, R., Angrist, B., Gatley, S.J., Logan, J., Ding, Y.S., Pappas, N., 1999. Association of methylphenidate-induced craving with changes in right striato-orbitofrontal metabolism in cocaine abusers: implications in addiction. Am. J. Psychiatry 156, 19-26.

Volkow, N.D., Wang, G.-J., Fowler, J.S., Logan, J., Jayne, M., Franceschi, D., Wong, C., Gatley, S.J., Gifford, A.N., Ding, Y.-S., Pappas, N., 2002. Nonhedonic food motivation in humans involves dopamine in the dorsal striatum and methylphenidate amplifies this effect. Synapse 44, 175-180, N. Y. N.

Volman, S.F., Lammel, S., Margolis, E.B., Kim, Y., Richard, J.M., Roitman, M.F., Lobo, M.K., 2013. New insights into the specificity and plasticity of reward and aversion encoding in the mesolimbic system. J. Neurosci. 33, 17569-17576.

Voorn, P., Vanderschuren, L.J.M.J., Groenewegen, H.J., Robbins, T.W., Pennartz, C.M.A., 2004. Putting a spin on the dorsal-ventral divide of the striatum. Trends Neurosci. 27, 468-474.

Vuillet, J., Kerkerian, L., Salin, P., Nieoullon, A., 1989. Ultrastructural features of NPY-containing neurons in the rat striatum. Brain Res. 477, 241-251.

Wakabayashi, K.T., Fields, H.L., Nicola, S.M., 2004. Dissociation of the role of nucleus accumbens dopamine in responding to reward-predictive cues and waiting for reward. Behav. Brain Res. 154, 19-30.

Wall, V.Z., Parker, J.G., Fadok, J.P., Darvas, M., Zweifel, L., Palmiter, R.D., 2011. A behavioral genetics approach to understanding D1 receptor involvement in phasic dopamine signaling. Mol. Cell. Neurosci. 46, 21-31.

Wall, N.R., De La Parra, M., Callaway, E.M., Kreitzer, A.C., 2013. Differential innervation of direct- and indirect-pathway striatal projection neurons. Neuron 79, 347-360.

Wang, H.B., Laverghetta, A.V., Foehring, R., Deng, Y.P., Sun, Z., Yamamoto, K., Lei, W.L., Jiao, Y., Reiner, A., 2006. Single-cell RT-PCR, in situ hybridization histochemical, and immunohistochemical studies of substance P and enkephalin co-occurrence in striatal projection neurons in rats. J. Chem. Neuroanat. 31, 178-199.
Wang, H.-B., Deng, Y.-P., Reiner, A., 2007. In situ hybridization histochemical and immunohistochemical evidence that striatal projection neurons co-containing substance P and enkephalin are overrepresented in the striosomal compartment of striatum in rats. Neurosci. Lett, 425, 195-199.

Watabe-Uchida, M., Zhu, L., Ogawa, S.K., Vamanrao, A., Uchida, N., 2012. Whole-Brain mapping of direct inputs to midbrain dopamine neurons. Neuron $74,858-873$.

Welter, M., Vallone, D., Samad, T.A., Meziane, H., Usiello, A., Borrelli, E., 2007. Absence of dopamine D2 receptors unmasks an inhibitory control over the brain circuitries activated by cocaine. Proc. Natl. Acad. Sci. U. S. A. 104, 6840-6845.

White, N.M., Salinas, J.A., 2003. Mnemonic functions of dorsal striatum and hippocampus in aversive conditioning. Behav. Brain Res. 142, 99-107.

White, N.M., Packard, M.G., Hiroi, N., 1991. Place conditioning with dopamine D1 and D2 agonists injected peripherally or into nucleus accumbens. Psychopharmacology (Berl.) 103, 271-276.

Wietzikoski, E.C., Boschen, S.L., Miyoshi, E., Bortolanza, M., dos Santos, L.M., Frank, M., Brandão, M.L., Winn, P., Da Cunha, C., 2012. Roles of D1-like dopamine receptors in the nucleus accumbens and dorsolateral striatum in conditioned avoidance responses. Psychopharmacology (Berl.) 219, 159-169.

Winocur, G., Mills, J.A., 1969. Effects of caudate lesions on avoidance behavior in rats. J. Comp. Physiol. Psychol. 68, 552-557.

Witten, I.B., Lin, S.-C., Brodsky, M., Prakash, R., Diester, I., Anikeeva, P., Gradinaru, V., Ramakrishnan, C., Deisseroth, K., 2010. Cholinergic interneurons control local circuit activity and cocaine conditioning. Science 330, 1677-1681.

Wu, Y., Parent, A., 2000. Striatal interneurons expressing calretinin parvalbumin or NADPH-diaphorase: a comparative study in the rat, monkey and human. Brain Res. 863, 182-191.

Xu, M., Moratalla, R., Gold, L.H., Hiroi, N., Koob, G.F., Graybiel, A.M., Tonegawa, S., 1994. Dopamine D1 receptor mutant mice are deficient in striatal expression of dynorphin and in dopamine-mediated behavioral responses. Cell 79, 729-742.

Yamamoto, B.K., Davy, S., 1992. Dopaminergic modulation of glutamate release in striatum as measured by microdialysis. J. Neurochem. 58, 1736-1742.

Yin, H.H., Knowlton, B.J., 2006. The role of the basal ganglia in habit formation. Nat. Rev. Neurosci. 7, 464-476.

Young, E.A., Dreumont, S.E., Cunningham, C.L., 2014. Role of nucleus accumbens dopamine receptor subtypes in the learning and expression of alcohol-seeking behavior. Neurobiol. Learn. Mem. 108, 28-37.

Zahm, D.S., Brog, J.S., 1992. On the significance of subterritories in the accumbens part of the rat ventral striatum. Neuroscience 50, 751-767.

Zahm, D.S., Heimer, L., 1990. Two transpallidal pathways originating in the rat nucleus accumbens. J. Comp. Neurol. 302, 437-446. 